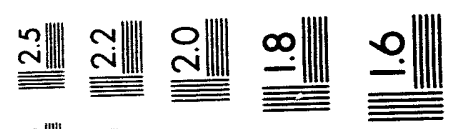

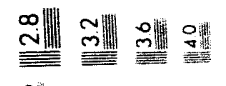

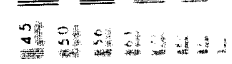

II

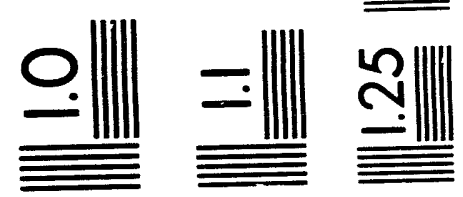



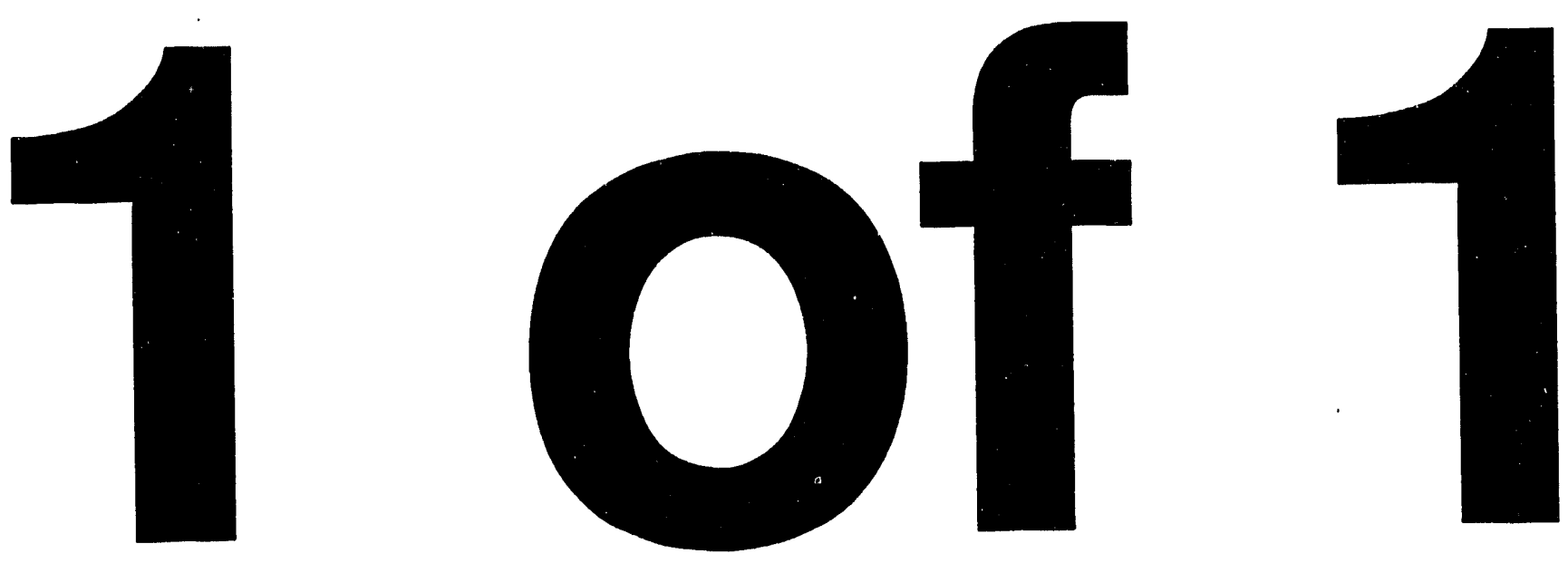
NUREG/CR-5968

ORNL/TM-12279

$\mathrm{RF}$

\section{Potential Change in Flaw Geometry of an Initially \\ Shallow Finite-Length \\ Surface Flaw During a \\ Pressurized-Thermal-Shock \\ Transient}

Manuscript Completed: June 1993

Date Published: September 1993

Prepared by

D. K. Shum, J. W. Bryson, J. (j. Merkle

Oak Ridge National Laboratory

Managed by Martin Marietla Energy Systems, Inc.

Oak Ridge National Laboratory

Oak Ridge, I'N 37831-6285

Prepared for

Division of Engineering

Office of Nuclear Regulatory Research

U.S. Nuclear Regulatory Commission

Washington, DC 20555-0001

NRC FIN B0119

Under Conitract No. DE-AC05-840R21400

(2) 


\begin{abstract}
This study presents preliminary estimates on whether an initially shallow, axially oriented, inner-surface finitelength flaw in a PWR-RPV would icnd to clongate in the axial direction and/or deepen into the wall of the vessel during a postulated P'IS transient. Results obtained for a family of modified elliptical flaws based on the assumptions of: (1) linear-clistic material response, and (2) cladding with same toughness as the base metal, indicate that a neariy semicircular flaw would likely propagate in the axial direction followed by propagation into the wall of the vessel. The'se results correspond to initiation within the fracture-toughness

will be a greater lendency for extensive axial propagation and for axial as opposed to radial propagation. The sensitivity of the numerical results and conclusions to the following three analysis assumptions are evaluated: (1) reference flaw geometry along the entire crack front and especially within the cladding region, (2) linearclastic vs elastic-plastic description of material response, and (3) basc-matcrial-only vs bimatcrial cladding-base vessel-model assumption. The sensitivity evaluation indicates that the analysis results are very sensitive to the above assumptions. This report is designated HSST Report No. 139.
\end{abstract} lower-shelf range. For the lower-transition range, there 


\section{Contents}

\section{Page}

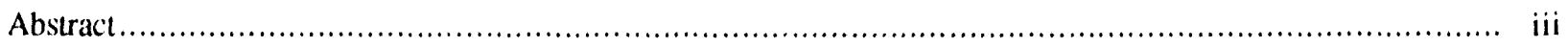

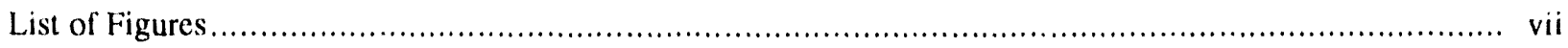

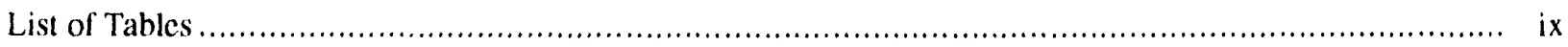

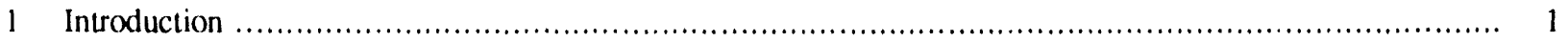

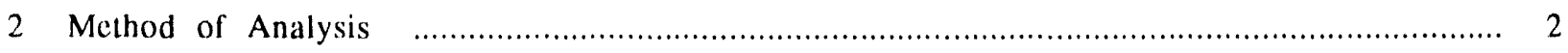

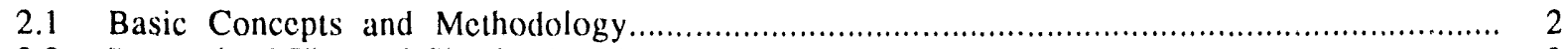

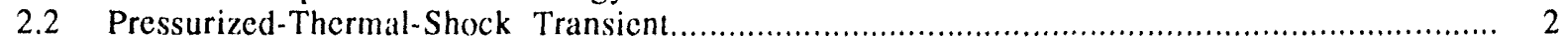

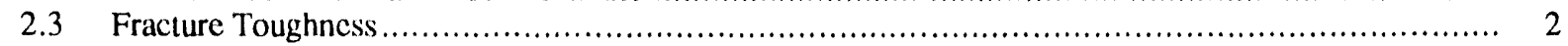

2.4 Finite-Element Model of Vessel and Initial Flaw Geometry ...........................................

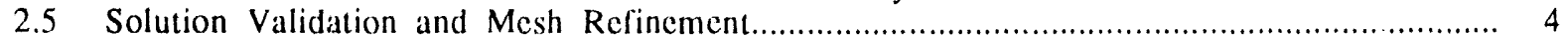

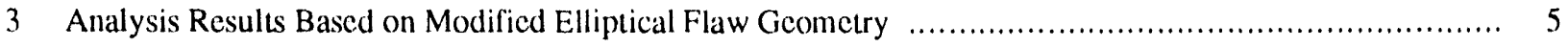

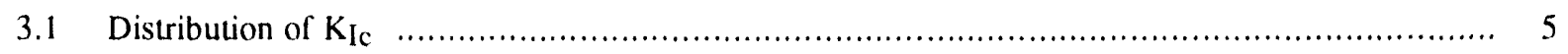

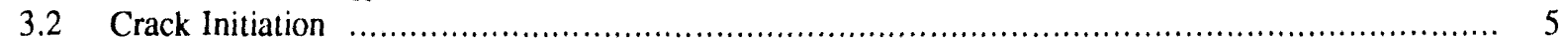

3.3 Potential for Flaw Stability After Initiation ............................................................ 5

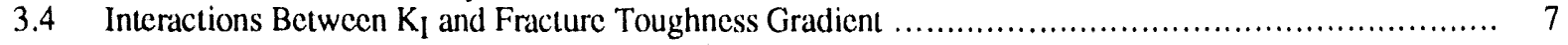

3.5 Implications of Higher Toughness in Cladding Than in Base Material........................................ 7

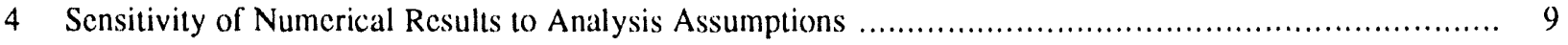

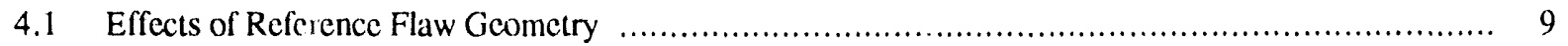

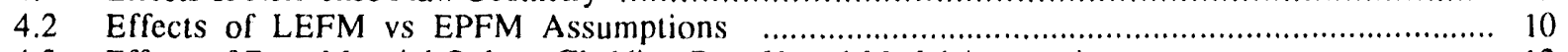

4.3 Effects of Base-Matcrial-Only vs Cladding-Base Vessel-Model Assumptions ............................. 12

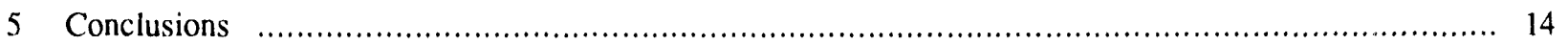

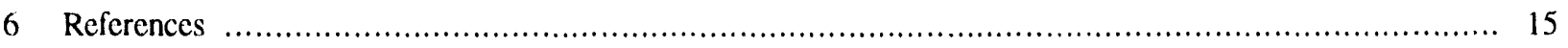

Appendix A: Closed-Form Solutions for $\mathrm{K}_{\mathrm{I}}$ for a Shallow Elliptical Surface Flaw in a Plate $\quad \ldots \ldots \ldots \ldots \ldots \ldots \ldots . . . \ldots 17$

Appendix B: Effects of Mesh Refinement on $\mathrm{K}_{\mathrm{I}}$ Values Along the Crack Front ...................................... 19 


\section{List of Figures}

1 Definition of pressurized-thermal-shock transient

2 (a) Finite-element model of reactor pressure vessel with an initially shallow, axially oriented inner-surface flaw; (b) close-up or region of vessel containing flaw.

3 Detail of nearly semicircular inner-surlace flaw constructed based on the modificd elliptical flaw geometry with aspect ratio $1: 1$.

4 Distribution of $\mathrm{K}_{\mathrm{Ic}}$ through the vessel wall up to a depth of $6.35 \mathrm{~mm}(0.25 \mathrm{in}$.) as a function of transient time $(t)$ in minutes.

5 Distribution of applied $\mathrm{K}_{\mathrm{I}}$ along the crack front of the ncarly semicircular modified elliptical flaw as a function of transient time $(t)$ in minutes, along with $\mathrm{K}_{\mathrm{Ic}}$ distributions relevant to consideration of initiation.

6 Distribution of applied $\mathrm{K}_{\mathrm{I}}$ along the crack front for two members $(1: 1,80: 1)$ of the modified elliptical family of surface flaws of a depth of $6.35 \mathrm{~mm}(0.25 \mathrm{in}$.) at $25 \mathrm{~min}$ into the transient

7 (a) Comparison of the various familics of llaw geometry for the case of a nominal (80:1) aspect ratio - (1) modified ellipse, (2) canoc, (3) cllipse. The vertical and horizonatal axes are drawn to vastly different scales to cmphasize the differences in crack-front geometries. (b) Crack-front geometries redrawn with more similar vertical and horizontal scales to emphasize the observation that the differences in llaw geometrics in (a) are minor in comparison with the overall geometry of the nominal flaw shape

8 Effects of reference flaw geometry on the computed $K_{I}$ values are minor for the case where aspect ratio is $1: 1$. Results are for $25 \mathrm{~min}$ into the transient.

9 Effects of reference flaw geometry on the computed $K_{I}$ values are significant for the case where aspect ratio is $80: 1$. Results are for $25 \mathrm{~min}$ into the transient.

10 True stress-true plastic strain curves for cladding and base material.

11 Effects of linear-clastic vs elastic-plastic description of material response on the computed $\mathrm{K}_{\mathrm{l}}$ values for the case where the aspect ratio of the modified elliptical flaw geometry is $1: 1$.

12 Effects of linear-clastic vs elastic-plastic description of material response on the computed $\mathrm{K}_{\mathrm{I}}$ values for the case where the aspect ratio of the modified elliptical flaw geometry is $80: 1$

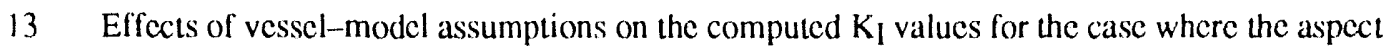
ratio of the modified elliptical flaw geometry is $1: 1$

14 Effects of vessel-model assumptions on the computed $\mathrm{K}_{I}$ values for the case where the aspect ratio of the canoe flaw geometry is $80: 1$.

B.1 Effects of mesh refinement in the circumferential direction of the vessel on the computed $\mathrm{K}_{\mathrm{I}}$ values.

B.2 Effects of one or two layers of elements in the cladding region on the computed $\mathrm{K}_{\mathrm{l}}$ values.

B.3 Effects of one or four layers of elements in the cladding region on the computed $\mathrm{K}_{\mathrm{I}}$ values 20 


\section{List of Tables}

Table

1 Vessel geometry and thermoclastic properties of the cladding and base material

A.1 Closed-form solutions for $\mathrm{K}_{1}$ at two locations along the crack front for the

"bimatcrial/clliptical llaw" combination 


\section{Introduction}

Regulatory Guide $1.154^{\prime}$ accepts the integrated pressurized-thermal-shock (IP'TS) medodelogy included in Refs, 2, 3, and 4 as an appropriate means for evaluating the integrity of nuclear reaclor pressure vesscls (RPVs) under pressurized-thermal-shock (PTS) loading conditons. All haws included in the probabilistic lratclure mechanics portion of the IP'TS methodology are surface flaws oriented in eilher a longitudinal or circumferential direction, and all liaws with depths less than $-40 \mathrm{~mm}(-1.57 \mathrm{in.})$ are assumed to be elfietively infinitely long [two dimensional (2-D)\} insolar as the calculation of the stress intensity factor $\left(K_{1}\right)$ is concerned. Three-dimensional (3-D) effects are included for deeper flaws. These particular assumplions regarding llaw length were mate because calculations pertormed for PTS-relaled confirmatory thermal-shock experiments 5 indicated that, al least in the absence of cladding, a semicircular shore surface llaw had a greater potential for initiation (onset of propagation) than a 2-D surface flaw of the same depth, and, once initiated, the short llaw would propigate in surface length to effectively become a 2-D llaw. This assumption was contirmed by the thermal-shock experiments. ${ }^{5}$ In other words, the existence of a short flaw resulted in the generation of a 2-D llaw before a 2-D llaw of the same depth could have initiated and propagated radially. Under these circumstances there wals no need in an IPTS analysis to perform calculations for the short flaw.

Similar comparison calculations were made lor PWR vessels under large-break loss-of-coolant ascident loading conditions. ${ }^{6}$ For the very limited number of cases considered, and contrary to the results obtained for the previously mentioned thermal-shock experiments, these results indicated that the short llaw had a somewhat less potential than a 2-D llaw for initiation.

To avoid a nonconservative approach with regard to "initial" nlaw length and still have an analytically manageable probabilistic fracture-mechanics model for the IPTS methodology, the 2-D initial flaw wats adopted in Ref. 1.

At the time the comparison calculations in Refs. 5 and 6 were made, the necessary 3-D fraclure analyses were very expensive and time consuming and, thus, were not performed extensively. Furthermore, there was a conservative way out of the ditemma (the assumption of a 2-D initial flaw). More recently, however, incentives for a more accurate evaluation have developed, and the practical numerical means for performing the more accurate evaluation have become available. A preliminary step toward achieving a more accurale evaluation is the subject of this study.
The objective of this study is to provide preliminary estimates on the potential change in flaw geometry of an initially shallow, axially oriented, inner-surface finite-length flaw in a PWR - RPV during the course of a postulated PTS transiont. These estimates have been obtained based on a series of scoping analyses using the finite-element method. Specifically, the question being addressed is whether a shallow finite-length surface law would lend to clongate in the axial direction and/or deepen into the wall of the vessel during the transient. Results from this study are expected to contribute toward an assessment of the degree of conservatism associaled with the use of $2-D$ axial flaws in a probabilistic fracture mechanics assessment of an RPV.

In the first part of the study, estimates have been oblained in accordance with the assumptions of conventional linear-clastic fracture-mechanics (LEFM) concepts. ${ }^{7}$ The thermoclastic properties of the cladding and base material are explicitly considered. The flaw geometry corresponds to a family of modified clliptical flaws characterized by the flaw's half-length to maximum depth (aspect ratio). Numerical results are presented for values of the aspect ratio of $1: 1$ and 8()$: 1$. Requirements for numerical convergence of the finite-clement results for this family of flaw geometries are examined.

In the second part of this study, the sensitivity of the numerical results and conclusions obtained in the first part of this study to some of the analysis assumptions are evaluated. ${ }^{8}$ Three specilic issues related to the analysis assumptions are considered. The first issue concerns the intluence of reference llaw geometry along the entire crack front, and especially within the cladding region, on the conclusions reported previously. The second issue concerns the influence of linear-elastic vs elastic-plastic description of material response on the analysis outcome. The third issue concerns the influence of modeling the RPV as a basematerial-only or as a bimaterial cladding-base metal cylinder on the analysis outeome. 


\section{Method of Analysis}

\subsection{Basic Concepts and Methodology}

Estmates of the potemial change in tlaw geometry during the frTs transient begin with a comparison of the mode 1 stress intensity factor $\left(K_{l}\right)$ values along the crack front of the initial shallow flaw with the static fracture toughness $\left(K_{I}\right)$ of the vessel material. The $K_{I}$ distributions are obtained using the finite-element method in accordance with the assumptions of conventional LEFM concepts. The static fracture toughness is assumed to vary through the wall of the vessel as a function of the through-wall fluence distribution and the through-wall temperature profiles during the transient.

Crack initiation is assumed to be mossible when $\mathrm{K}_{\mathrm{I}}$ exceeds $K_{i c}$ at any point along the initial crack front. It is then assumed that crack initiation at the critical lowation introduces dynamic loading effects along the remainder of the crack front. Consequently, the dynamic fracture toughness, $\mathrm{K}_{I d}$, of the vessel material is assumed to determine that portion of the crack front that participates in crack initiation.

While not explicilly considered in this study, extension of the present methodology beyond the initial initiation can be considered whereby a stable flaw geometry subsequent to initiation is assumed possible when $\mathrm{K}_{\mathrm{I}}$ along the initiated crack front falls to the crack-arrest toughness $\left(\mathrm{K}_{1 \mathrm{a}}\right)$. The flaw is then assumed to maintain its new geometry until a later time in the transient when $\mathrm{K}_{\mathrm{l}}$ again exceds $\mathrm{K}_{l}$ somewhere along the new crack front, at which time the flaw geometry will again change in accordance with the interpretation method outlined above.

\subsection{Pressurized-'Thermal-Shock Transient}

The PTS transient considered in this study is indicated in Fig. 1, which simulates the occurrence of a smallbreak loss-of-coolant accident (SBLOCA). The vesisel is assumed to operate at $268^{\circ} \mathrm{C}\left(515^{\circ} \mathrm{F}\right)$ prior to the transicnt. The cooling water temperature is also at $268^{\circ} \mathrm{C}\left(515^{\circ} \mathrm{F}\right)$ prior to the transieni.

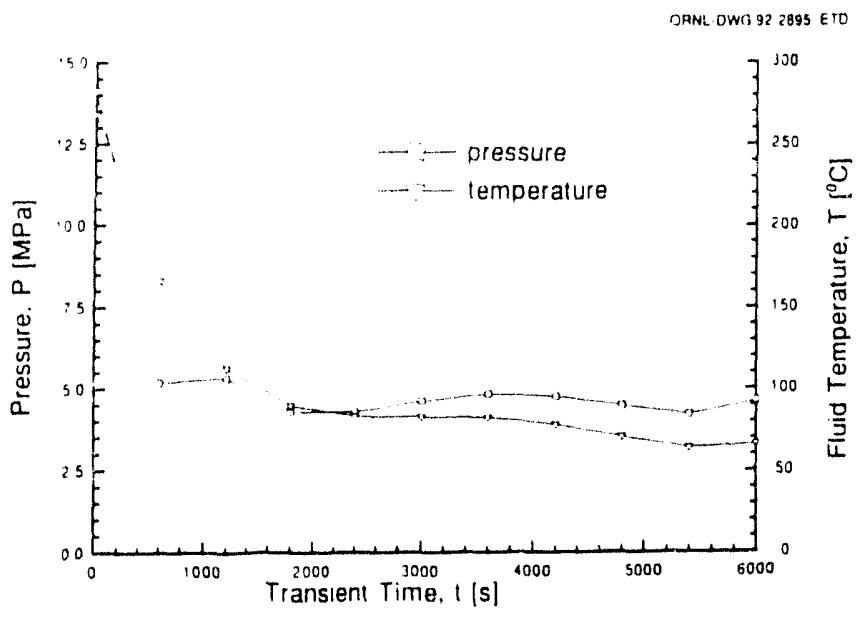

Figure 1 Definition of pressurized-thermalshock transient

\subsection{Fracture Toughness}

The static fracture toughness $\left(\mathrm{K}_{\mathrm{IC}}\right.$ ) as a function of $\mathrm{T}$ RT NDT for the vessel base material is identified with the lower-bound (IPTS-mean minus Iwo standard deviations) ASME curve. ${ }^{9} \triangle \mathrm{RT}_{\text {NDT }}$ is determined from Reg. Guide 1.99, Rev. 2 (base metal) ${ }^{10}$ based on an assumed chemistry of $0.29 \% \mathrm{Cu}$ and $0.6 \% \mathrm{Ni}$, vessel inner-surlace fluence of $1.7 \times 10^{19} \mathrm{n} / \mathrm{cm}^{2}(\mathrm{E}>$ $1 \mathrm{MeV}$ ), anci a fow-temperature-irradiation additional RTNDT shift of $27.8^{\circ} \mathrm{C}\left(50^{\circ} \mathrm{F}\right){ }^{*}$ The initial RT NDT is assumed to be $-1.1^{\circ} \mathrm{C}\left(30^{\circ} \mathrm{F}\right)$. The dynamic fracture toughness $\left(\mathrm{K}_{\mathrm{Id}}\right)$ for the vessel base material is conscrvatively represented by $\mathrm{K}_{\mathrm{la}}$.

In addition, it is assumed that the clad-base interface is fully bonded and that the interface, along with the regions adjoining the interface such as the heat-affected

\footnotetext{
${ }^{*} A$ value of $27.8^{\circ} \mathrm{C}\left(50^{\circ} \mathrm{F}\right)$ implies that the effective operating temperature over the history of the vessel is $260^{\circ} \mathrm{C}$ $\left.(50)()^{\circ} \mathrm{F}\right)$.
} 
zones, share the fracture toughness of the base material. The cladding is also conservalively assumed to share the fracture toughness of the base material. The findings of this study, when the cladding loughness is assumed to be higher than that of the base material, are addressed subseyuent to the presentation of analysis results.

\subsection{Finite-Element Model of Vessel and Initial Flaw Geometry}

A finite-element model of the beltine region of an RPV is generated with the ORNL program ORMGEN as indicated in Fig. 2(a). ${ }^{11}$ An initially shallow, axially oriented, inner-surface finte-length llaw is assumed to exist within this region as indicated in Fig. 2(b). From symmetry considerations only one-fourth of the vessel is modeled. Quadratic elements are used throughout the model. The vessel is modeled with a $2.769-\mathrm{mm}$ thick (0.1())-in.) stainless steel cladding on the inner surface. Details on the vessel geometry along with the thermoclastic properties of the cladding and batse material are listed in Table 1.

In the first part of this study the initial llaw geometry corresponds to a nearly semicircular thaw with a maximum flaw depth of $6.35 \mathrm{~mm}$ (0.25 in.), as indicaled in Figs. 2(b) and 3. The initial flaw geometry is constructed based on a family of liaw geometries herein denoted as modified ellipses. This family of llaw geometries is constructed with a crack lront that is elliptical in the base material and is a straight line perpendicular to the vessel's inner-surlace in the cladding region.

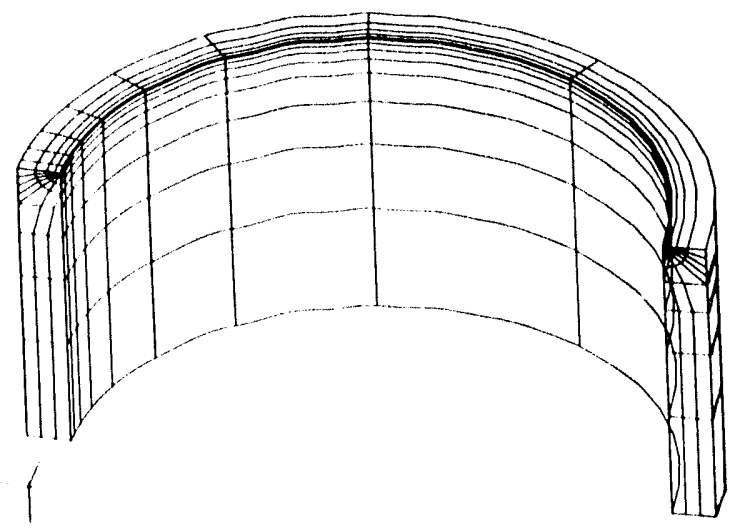

Figure 2(a) Finite-element model of reactor pressure vessel with an initially shallow, axially oriented inner. surface flaw

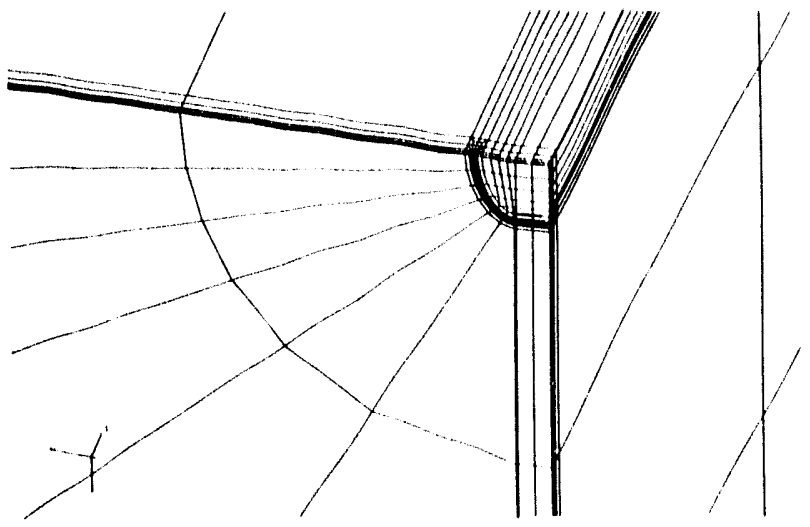

Figure $2(b)$ Close-up of region of vessel containing flaw

Table 1. Vessel geometry and thermoelastic properties of the cladding and base material

Vessel (ieometry:

Inner vessel radius $=1.38 \mathrm{~cm}(54.5 \mathrm{in}$.

Wall thickness $=20 \mathrm{~cm}(7.875 \mathrm{in}$.)

Vessel length $=30.5 \mathrm{~cm}(120 \mathrm{inl}$.)

Cladding Thickness $=0.277 \mathrm{~cm}(0.109 \mathrm{in}$.

Cladding Thermal-lilastic Material Properties:*

Modulus of elasticity $(\mathrm{E})=186(\mathrm{iPa}$
$(27,(0)() \mathrm{ksi})$

Poisson's ratio $(v)=0.3$

Thermal expansion coeflicienl $\left(\alpha_{\text {clad }}\right)=$ $1.8 \mathrm{E}-5 /{ }^{\circ} \mathrm{C}\left(9.9 \mathrm{E}-6 /{ }^{\circ} \mathrm{F}\right)$

Thermal conductivity $(k)=17 \mathrm{~W} / \mathrm{m}-{ }^{\circ} \mathrm{C}$ (10) BTU/h-fl- $\left.{ }^{\circ} \mathrm{F}\right)$

Specific heal $\left(c_{p}\right)=5(10) \mathrm{J} / \mathrm{kg}^{\circ}-{ }^{\circ} \mathrm{C}$ (0).12 BTU $\left./ \mathrm{b}-{ }^{\circ} \mathrm{F}\right)$

Density $(\rho)=7820 \mathrm{~kg} / \mathrm{m}^{3}\left(488 \mathrm{lb} / \mathrm{ft}^{3}\right)$

Base Metal Thermal-Liastic Material Properties:

Modulus of elasticity $(E)=193 \mathrm{CiPa}$
$(28,($ ()) k ki $)$

Poisson's ratio $(v)=(1) .3$

Thermal expansion soefficionl $\left(\left(x_{b_{\text {bas }}}\right)=1.41 \mathrm{E}-5 /{ }^{\circ} \mathrm{C}\right.$

$\left(7.85 \mathrm{E} \cdot 6 /{ }^{\circ} \mathrm{F}\right)$

Thermal conductivity $(k):=42 \mathrm{~W} / \mathrm{ml}{ }^{\circ} \mathrm{C}$ $\left(24 \mathrm{BTU} / \mathrm{h}-\mathrm{ft} \cdot{ }^{\circ} \mathrm{F}\right)$

Specific heal $\left(c_{p}\right)=5(0) \mathrm{J} / \mathrm{kg} \cdot{ }^{\circ} \mathrm{C}$ (0).12 B'TU/R6. ${ }^{\circ}$.)

Densily $(\rho) \div 7 \times 20 \mathrm{~kg} / \mathrm{ml}^{3}\left(488 \mathrm{lb} / \mathrm{ft}^{3}\right)$

Coefficient of Convective Heat Transfer $=$

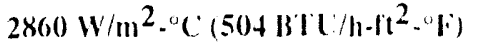

\footnotetext{
${ }^{*}$ No temperature dependence of material properties included in analyses.
} 


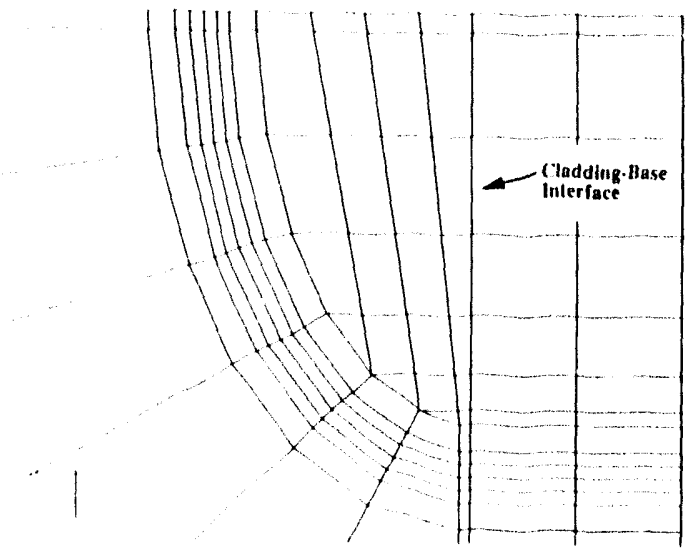

Figure 3 Detail of nearly semicircular innersurface flaw constructed based on the modified elliptical flaw geometry with aspect ratio 1:1

A maximum flaw depth of $6.35 \mathrm{~mm}(0.25 \mathrm{in}$.) is chosen for the initial flaw geometry based on findings from probabilistic fracture mechanics safely assessments of RPVs subject to a postulated pressurizedthermal-shock transient. ${ }^{2-4}$ As discussed in the Introduction, current probabilistic analyses that involve a "shallow" flaw depth assume a 2-D plane strain model of both the vessel and flaw geometry, in that both the vessel and flaw are assumed to be infinite in length in the axial direction of the vessel. Available analysis results suggest that, for SBLOCA transients, the majority of surface flaws causing nonarresting fractures have depths close to $6.35 \mathrm{~mm}(0.25 \mathrm{in}$.).

\subsection{Solution Validation and Mesh Refinement}

The finite-clement calculations are carried out using the computer program ABAQUS. ${ }^{13}$ Values of the mode I stress intensity factor $\left(\mathrm{K}_{\mathrm{I}}\right)$ along the crack front of a given model are determined from the associated Jintegral values using the plane strain conversion formula and assuming a value of the Young's modulus and Poisson's ratio for the base material. The Jintegral values are determined using the J-integral option within ABAQUS.
A limited number of comparison calculations have been performed using the computer program ADINA. ${ }^{14}$ In the case of ADINA, the J-integral values are determined using the ORNL post-processing program ORVIRT. ${ }^{15}$ Relatively good agreement in calculated $K_{1}$ values along the crack front is found with these two programs.

Alternative (approximate) validation of the $K_{I}$ value, at both the deepest point of the crack and at the inner surface of the vessel, has been performed based on available solutions for a shallow clliptical surface flaw in a plate. Results from this validation are also in good agreement with the finite element results as discussed in Appendix $\mathrm{A}$.

The effects of mesh refinement for modeling (1) the behavior of the cladding and (2) the global behavior of the vessel and its effects on the calculated $\mathrm{K}_{I}$ values are examined in Appendix B. It is observed that for the analysis conditions examined in this study, sensitivity of the computed $\mathrm{K}_{\mathrm{I}}$ values to mesh-refinement effects in the cladding region is minimal but is significant for such effects in the circumferential direction of the vessel.

In this study, in order to keep the computational requirements manageable, finite-element results have been obtained based on models of the vessel with cither (1) one element in the cladding region and 12 elements in the circumferential direction or (2) two elements in the cladding region and ten elements in the circumferential direction. Since only minor differences in analysis results exist between these two types of model, no attempt is made to identify the type of finiteelement model associated with the anaiysis results to be presented. 


\section{Analysis Results Based on Modified Elliptical Flaw Geometry}

\subsection{Distribution of $\mathrm{K}_{\mathrm{Ic}}$}

Variation of the static fracture toughnes (KIc) (IPTSmean minus two standard deviations) through the vessel wall up to a depth of $6.35 \mathrm{~mm}(0.25 \mathrm{in}$.) is indicated in Fig. 4 as a function of transient time from 10 to $25 \mathrm{~min}$. Note that for transient times beyond -20 min, the distribution of $\mathrm{K}_{\mathrm{I}}$ is essentially constant over this range of wall depth.

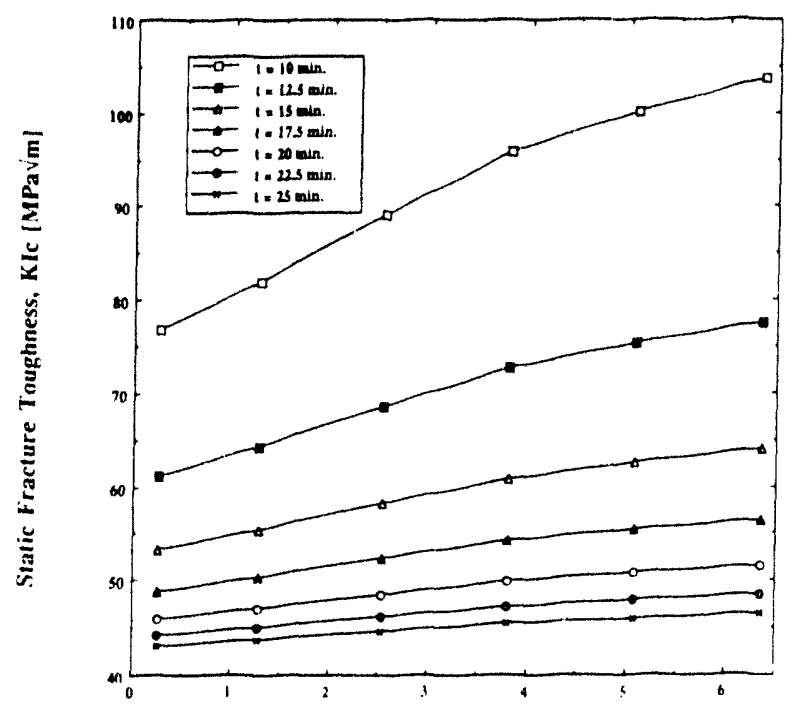

Vessel Wall Depth Measured Hrom Inner-Surface $[\mathrm{mm}$ !

Figure 4 Distribution of $\mathrm{K}_{\mathrm{Ic}}$ through the vessel wall up to a depth of $6.35 \mathrm{~mm}(0.25 \mathrm{in}$.) as a function of transient time $(t)$ in minutes

\subsection{Crack Initiation}

Variation of the applied $\mathrm{K}_{\mathrm{I}}$ values along the crack front of the nearly semicircular flaw (Fig. 3) is indicated in Fig. 5 as a function of transient times from $0.1 \mathrm{~min}$ to $25 \mathrm{~min}$. Note that the $\mathrm{K}_{\mathrm{I}}$ values achieve their maximum values at $\sim 20 \mathrm{~min}$ into the transient. Included in Fig. 5 are the $\mathrm{K}_{\mathrm{Ic}}$ distributions through the vessel wall at four transient times of interest.

Results shown in Fig. 5 indicate that $\mathrm{K}_{\mathrm{Ic}}$ is exceeded at the location where the crack front intersects the inner surface of the vessel at $\sim 20$ to $25 \mathrm{~min}$ into the transient. For simplicity, it is assumed that initiation first takes place at 25 min into the transient with the $\mathrm{K}_{\mathrm{Ic}}$ distribu- tion approximately constant at $\mathrm{K}_{\mathrm{lc}}=44 \mathrm{MPa} \sqrt{\mathrm{m}}(40$ $\mathrm{ksi} \sqrt{\mathrm{in}}$.) up to a wall depth of $6.35 \mathrm{~mm}(0.25 \mathrm{in}$.). Note that the $K_{1}$ value at the inner surface of the vessel cannot be strictly evaluated using the present finite element formulation. However, one may interpret the above result to imply that initiation will occur near the free surface.

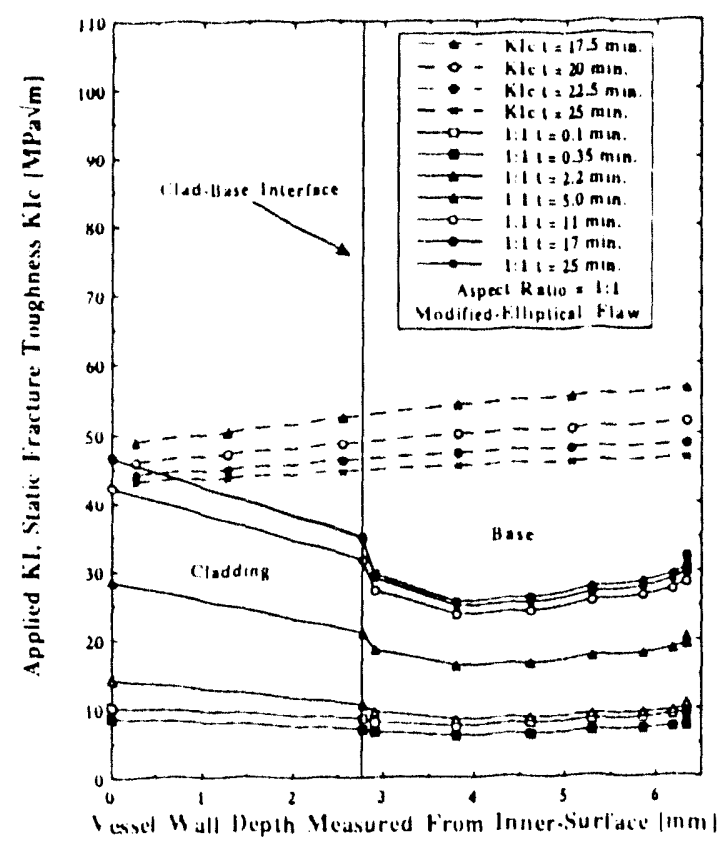

Figure 5 Distribution of applied $\mathrm{K}_{\mathrm{I}}$ along the crack front of the nearly semicircular modified elliptical flaw as a function of transient time $(t)$ in minutes, along with $K_{\text {Ic }}$ distributions relevant to consideration of initiation

\subsection{Potential for Flaw Stability After Initiation}

The ratio $K_{l a} / K_{l c}$ corresponding to $K_{l c}=44 \mathrm{MPa} \sqrt{\mathrm{m}}$ (40) ksi $\sqrt{\text { in. }) ~ i s ~} 0.8$, so that $K_{\text {Id }}$ is estimated as 35.2 $\mathrm{MPa} \sqrt{\mathrm{m}}(40 \mathrm{ksi} \sqrt{\mathrm{in} .})$. The initial nearly semicircular flaw will first elongate in the axial direction. Strictly speaking, only that portion of the crack front within $2.54 \mathrm{~mm}(0.1 \mathrm{in}$.) of the inner surface, which is confined within the cladding, would extend at this time in the transient. 
For the purr sse of ascertaining whedler the initialed portion of the flaw would arrest and resull in a slable flaw, the $\mathrm{K}_{1}$ value for an clongaled surfice llaw wilh a depth of $6.35 \mathrm{~mm}(0.25 \mathrm{in}$.) and a hall-lenght of $5(18$ mm (20 in.) (aspect ratio of $80: 1$ ) al 2.5 min into the transient is indicated in Fig. 6, along with the distribution at initiation for the nearly semicircular flaw (1:1). $\mathrm{It}$ is observed that at $25 \mathrm{~min}$ the value of $\mathrm{Kl}$ along most of the clongated crack fromt is ahowe $K_{l_{i 1}}=35.2$ $M P a \sqrt{m}(32 \mathrm{ksi} \sqrt{\mathrm{in} .})$.

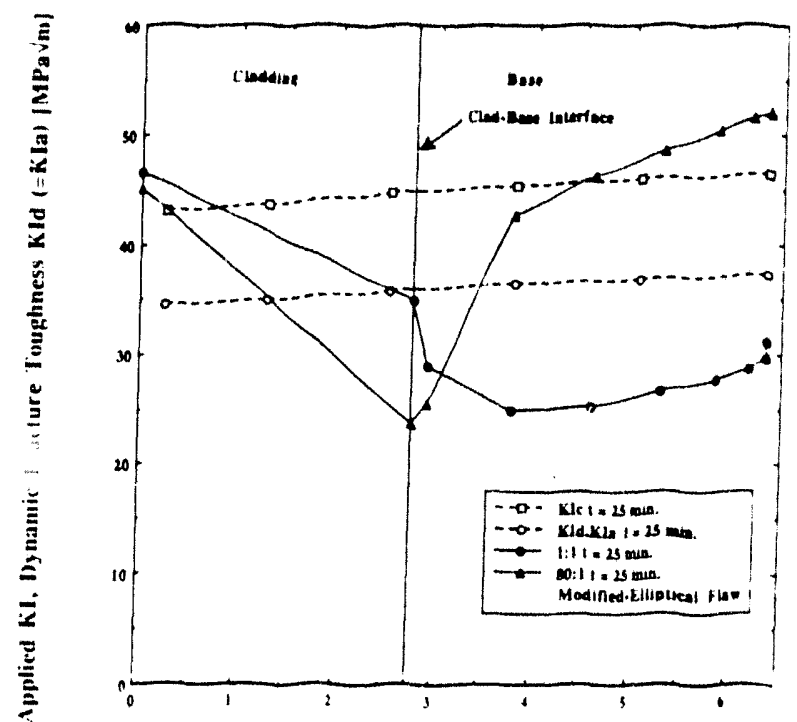

Vessel Wall Depth Measured From Inner Surface $|\mathrm{mm}|$

Figure 6 Distribution of applied $K_{1}$ along the crack front for two members $(1: 1,80: 1)$ of the modified elliptical family of surface flaws of a depth of $6.35 \mathrm{~mm}$ $(0.25$ in.) at $25 \mathrm{~mm}$ into the transient

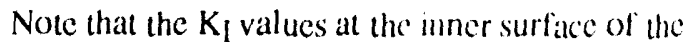
vessel, for the modified elliptical family of elongated flaws with a depth of $6.35 \mathrm{~mm}(0.25 \mathrm{in}$.) considered in this study, do not appear to decrease significantly with increase in axial flaw dimension. It appears reasonable to expect that any increase in depth of the flaw would elevate the applied $K_{I}$ value near the inner surface of the vessel. Therefore, the implication is that the nearly semicircular flaw would extend along the entire length of the vessel during the transient.

In the absence of $K_{I}$ values for intermediate llaw geometries, it can only be surmised that, for the particular analysis conditions assumed in this study, the nearly semicircular flaw will initially extend in the axial direction and eventually be followed by propagation into the wall of the vessel. Crack arrest in the axial direction within the belt-line region is not expected. Without additional cakculations, it is not possible to conclude whether the flaw would arrest in the depth direction.

It is appropriate at this point of the discussion to cstablish connections between the present results for 3-D, finite-kngth flaws with a depth of $6.35 \mathrm{~mm}$ (0.25 in.) and 2-D results based on the assumption of an axially infinite surface flaw of the same depth. The value of $K_{1}$ for the associated 2-D) llaw will a depth of $6.35 \mathrm{~mm}$ (0.25 in.) at $20 \mathrm{~min}$ into the transient, as determined from OCA-P, 12 is $-55 \mathrm{MPa} \sqrt{\mathrm{m}}$ (50) ksi $\sqrt{\mathrm{in} \text {.). }}$. Consequently, the initially shallow, nearly semicircular (1:1) 3-D, linite-length flaw has less polential for initiation than a 2-D flaw of the same depth. However, since the finite-leng $h$ flaw is expected to extend along the entire length of the vessel during the transient, the evident conservatism associated with the use of a 2 -D llaw geometry is of no conseyuence in the present deterministic evaluation. On the other hand, without additional calculations, it is not possible to quantify the degree of conservatism associalted with the use of a 2-D flaw geometry in a probabilistic evaluation in which the loughness of the base material, annong other parameters, is treated in a statistical fashion. It is noted that in a probabilistic analysis involving a SBLOCA transient, the majority of calculated initiations associated with a flaw depth of alpproximately $6.35 \mathrm{~mm}(0.25$ in.) lead to nonarresting fractures of the vessel.

The above discussion on the relative conservatism associated with a 2.-D vs 3-D flaw geometry does not include the possib e inlluence of warm prestress as a function of the flaw geonetry 16 Based on the $\mathrm{K}_{\mathrm{l}}$ results presented in Fig. 5, a 2-D) flaw is likely wo initiate at a slightly earlier time during the transient as compared to the 3-D flaw and is of little conseguence in the present discussion. However, it is conceivable that for some combination of PTS-transient conditions a 2-D flaw would be predicted to initiate $\left(K_{I}=K_{l c}\right)$ prior to allaining a maximum value in $\mathrm{K}_{1}$, whereas a 3-D flaw would be predicted to initiate $\left(K_{I}=K_{l c}\right)$ subsequent to the altainment of a maximum value in $\mathrm{K}_{1}$. Under these circumstances, for example, incorporation of warm prestesess effects would result in the prediction of crack initiation for the 2-D llaw geometry but not for the 3-D flaw geometry. Note that current guidelines for performing PTS safely analysis do not permit the inclusion of warm prestress effects.' 


\subsection{Interactions Between $\mathrm{K}_{\mathrm{I}}$ and Fracture 'Toughness Gradient}

Within the context of the interpretation method described above, it is clear thall whether a flaw will lend to extend exclusively in evither the axial or depth direction or a combination of both directions is strungly dependem on the values of $K_{l} / K_{l}, K_{l} / K_{l d}$, and $K_{1} / K_{\text {la }}$, allong the crack fromt and the value of $K_{1} / K_{\text {la }}$ initially and as the crack Iront extends. This observation can be illustrated by reconsidering the nearly semicircular flaw just allalyed. The $\mathrm{K}_{1}$ value is highest hear the inner surface within the cladding, which would lend to caluse the flaw (1) (longate initially. However, as the llaw progressively elongates in the axial direction, the $K_{1}$ vallue at the deepest point would increase while the value near the inner surlace would decreasse, with the eventual outcomic that the $\mathrm{K}_{1}$ value at the deepest point becomes the largess value rllong the crack front. This is the case for the elongated 8(): I llaw. Note that for the songalled 80): I llaw

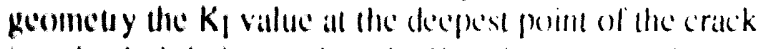

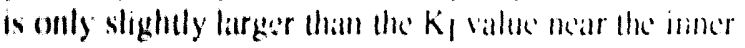
vurlice.

The tendency for extensive avial extension without arrest increases with increasing $K_{1} / K_{l_{i n}}$, and the lendency for axial as opposed to radial extension increases with increasing positive riddial gradient in wughness. As indicaled in Fig. 4, the wughness gradient is quite flat for the problem evaluated in this report. Thus, for a case involving a stecper loughness gradient, the relative potential for axial extension would be even greater than observed in this study. For the fluence-related embritlement, He PTS tratnsient, and the time in the transient (25 min) selected for this study, the vessel temperatures in the vicinity of the shallow flaw correspond to the lower shell of the loughness curve. This explains the flat toughness distribution in Fig. 4. For a casce imvolving less embritlement, the toughness gradicint would be steceper and $\mathrm{K}_{\mathrm{l}} / \mathrm{K}_{\mathrm{la}}$ would be larger; thus there would be a more extensive axial extension of the flaw and less polential for radial extension, if initiation took place. Of course, the less the embritllement, the lower the potential for initiation.

\subsection{Implications of Higher Toughness in Cladding Than in Base Material}

Note that estimates of potential flaw-geometry change are very sensitive to assumptions regarding the fracture response of the cladding. In this study, it has been assumed that the claddling shares the toughness of the base material. A more realistic view may be that the cladding is tougher than the base material.

Available experimental data for the irradiated ductiletearing toughness of a stainless steel cladding material 17 indicate that, at $25 \mathrm{~min}$ into the present transient, which corresponds $t o$ a vessel inner-surface temperature of $113^{\circ} \mathrm{C}\left(236^{\circ} \mathrm{F}\right)$, the cladd ding toughness is $\sim 143$ $\operatorname{MPa} \sqrt{\mathrm{m}}(130 \mathrm{ksi} \sqrt{\mathrm{in}}$ ). IThe value of $143 \mathrm{MPa} \sqrt{\mathrm{m}}$ (130) ksi $\sqrt{\text { in }}$ ) corresponds to a fluence level of $2.41 \times$ $10^{19} \mathrm{n} / \mathrm{cm}^{2}(\mathrm{E}>1 \mathrm{McV})$, which is higher than the lluence assumed in this study.I If one incorporates this observation into the interpretition method, the results presented in Fig. 5 suggest that the nearly semicircular flaw would not initiate during the course of the postulated PTS transient. This observation is based on the fact that, during the course of the transient, $\mathrm{K}_{\mathrm{Ic}}$ is exceeded only within a narrow region of the cladding even at $20 \mathrm{~min}$ into the transient, which corresponds approximately to the time of maximum loading. Beyond $20 \mathrm{~min}$ both the applied $\mathrm{K}_{\mathrm{I}}$ and $\mathrm{K}_{\mathrm{Ic}}$ fall with time, and it is not anticipated that $K_{1}$ would exceed $K_{l c}$ thereafter for the conditions considered in this study.

The above observation is significant in view of the fact that, at present, analysis results from probabilistic fracture mechanics safety assessments of RPVS subjected to a postulated SBLOCA transient show that a significant portion of the predicted vessel failures are due to the initiation and propagation of shallow 2-D llaws with a depth of $\leq 6.35 \mathrm{~mm}$ (0.25 in.). As discussed in the Introduction, implici! in the use of 2-D flaws is the assumption that a shallow inner-surface linite-length llaw wouldextend in the axial direction of the vessel prior to its possible penetration into the wall of the vessel. The assumption of cladding toughness higher than that of the base material thus appears to represent one avenue through which the tendency for a 3-D, finite-length surlace llaw to convert to an essentially 2-D surface flaw could to inthibited. The present findings thus suggest that a significant level of conservatism may be associated with the use of 2-D surface llaw geometries and the assumption of identical toughnesses for both the base and cladding matcrial. 
The possibility of subclad crack extension, while not explicitly considered in this study, represent an alternate avenue through which the tendency for a 3-D surface flaw to convert to a 2-D surface flaw could be inhibited. Indeed, subclad crack extension in the form of crack tunneling (both axial lengthening and radial deepening of flaw geometry) have been observed experimentally. ${ }^{18}$ In Ref. 18 , it is reported that initially part-through finite-length surface and subclad cracks extend beneath the cladding to become effectively 2-D subclad cracks under thermal-shock loading.
Finally, it is emphasized that the sensitivity of the present findings to variability in the toughness of the base material has not been investigated. This study models the base material with only a single value of $\triangle R T$ NDT. It is anticipated that a full investigation that incorporates, among other parameters, the variability in toughness of the base material, would be able to more realistically identify the population of finite-length flaws that would not propagate to become 2-D flaws. 


\section{Sensitivity of Numerical Results to Analysis Assumptions}

In the second part of this study, the sensitivity of the numerical results and conclusions ohtained in the first part of the study to some of the analy'sis assumptions are evaluated. Three specific issues related to the analysis assumptions are considered. The first ssiue concerns the influence of reference llaw geometry along the entire crack front, ind especially within the cladding region, on the conclusions reported previously. That is, to what extent were the results from the first part of this study dependent on the specific family of flaw geometries considered, all of which can be characterized by nominally identical aspect ratios? The second issue concerns the intluence of linear-elastic vs elastic-plastic description of material response on the analysis outcome. This is important since existing computer programs for IPTS-type analysis assume linear-elastic material responsic only'. The third issue concerns the influence of modeling the RPV as a basematerial-only or as a bimaterial cladding-base cylinder. This is important since available information on the thermomechanic al properties of the cladding material is relatively scarce as compared with the hatse material, especially under irradiated conditions.

As discussed in Sect. 3, maximum loading of the flawed cylinder, in terms of the magnitude of the applied stress intensity factor $K_{1}$, occurs al 20 min into the transient. In subsequent discussions, analysis results are presented at $25 \mathrm{~min}$ into the transient.

\subsection{Effects of Reference Flaw Geometry}

Three families of crack-front geometries have been considered: (1) modified ellipse: this is the flaw geometry considered in the first part of the study, in which the crack-front is elliptical in the base material but is straight and perpendicular to the vessel's imer surface in the cladding region; (2) canoe: the crackfront in the base material is essemtially a straight line parallel to the vessel's longitudinal axis with two semicircular regions near the ends, intersecting the clad/base interface at 90 degrees and with the crack front in the cladding being straight and perpendicular to the vessel's inner surface; (3) ellipse: the crack-front is elliptical in shape throughout the base and cladding material.

Comparison of the various families of flaw geometries is indicated in Figs. 7(a) and (b) for the casc of a nominal $(80: 1)$ aspect ratio. In Fig. 7(a), the verical and horizontal axes are drawn to vastly different scales to emphasize the differences in crack-front geometrics. In Fig. 7(b), crack-front geometrics are redrawn wilh more similar vertical and horizonlal scales 10 emphasize the observation that the differences in flaw geometries in Fig. $7(a)$ are minor in comparison with the overall geometry of the nominal flaw shape.

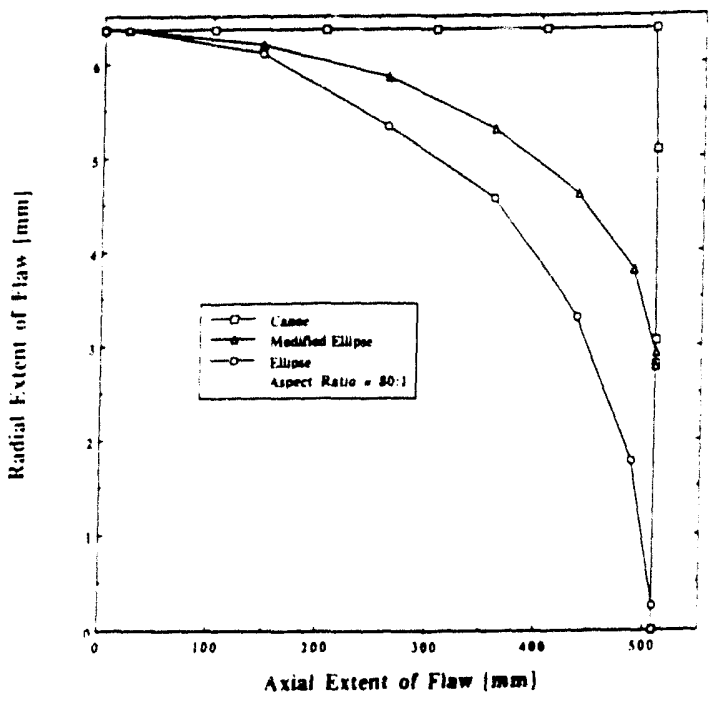

Figure $7(a)$ Comparison of the various families of flaw geometry for the case of a nominal (80:1) aspect ratio - (1) modified ellipse, (2) canoe, (3) ellipse. The vertical and horizontal axes are drawn to vastly different scales to emphasize the differences in crackfront geometries

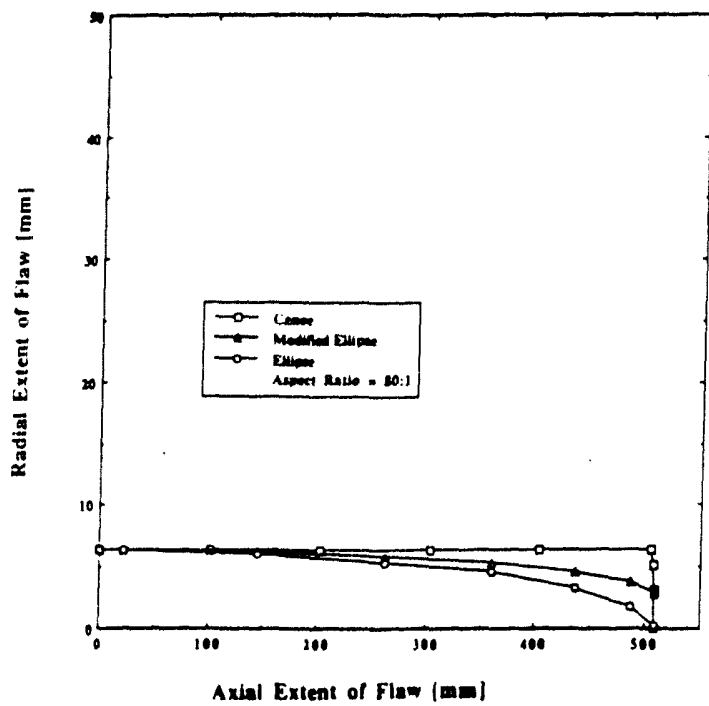

Figure $7(b)$ Crack-front geometries redrawn with more similar vertical and horizontal scales to emphasize the observation that the differences in flaw geometries in (a) are minor in comparison with the overall geometry of the nominal taw shape 
Effects of reference flaw geometry on the computed $\mathrm{K}_{\mathrm{l}}$ values are isolated via a series of LEFM scoping calculations in which the vessel is assumed to be made of base-material only. In Fig. 8, results are presented for the modified elliptical and elliptical llaw geometry based on a common aspect ratio of 1:1. The modified cllipse is thus nearly semicircular while the ellipse is exactly semicircular in shape. In Fig. 9, results are presented for all three flaw geometries based on a common aspect ratio of 8()$: 1$.

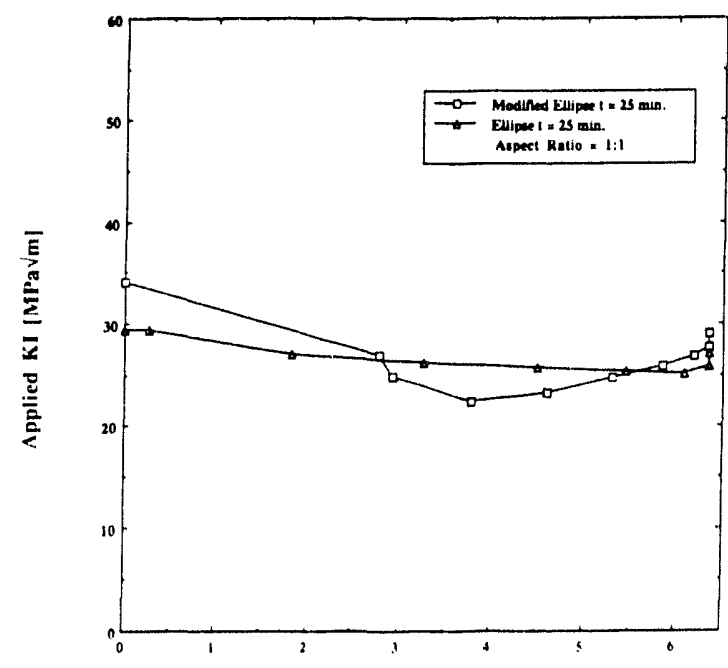

Vessel Wall Depth Measured from Inner-Surface [mm]

Figure 8 Effects of reference flaw geometry on the computed $K_{I}$ values are minor for the case where aspect ratio is $1: 1$. Results are 25 min into the transient

Analysis results indicaled in Fig. 8 suggest minor effects of reference flaw geometry on the computed $\mathrm{K}_{1}$ values for the calse where the aspect ratio is 1:1. On the other hand, analysis results indicated in Fig. 9 suggest that the crack-front geometry within the cladding can significantly influence the computed $\mathrm{K}_{\mathrm{I}}$ values along the crack front within the cladding region, especially for the case of elongated surface flaws with large aspect ratios. Specifically, for the case where the aspect ratio is 80:1, analysis results indicate that (a) computed $\mathrm{K}_{\mathrm{I}}$ values at the deepest point of the crack front agree for all three flaw geometries, (b) computed $\mathrm{K}_{\mathrm{I}}$ values along the cladding portion of the crack front near the inner-surlace can differ by up to a factor of 5 among the flaw geometries considered, with the maximum value being for the canoc llaw geometry and the minimum value being for the ellipse flaw geometry. Results in Figs. 8 and 9 together appear to suggest that the computed $\mathrm{K}_{I}$ values along the crack lront within the cladding region increase wilh increasing curvature of the crack fromt in that region.

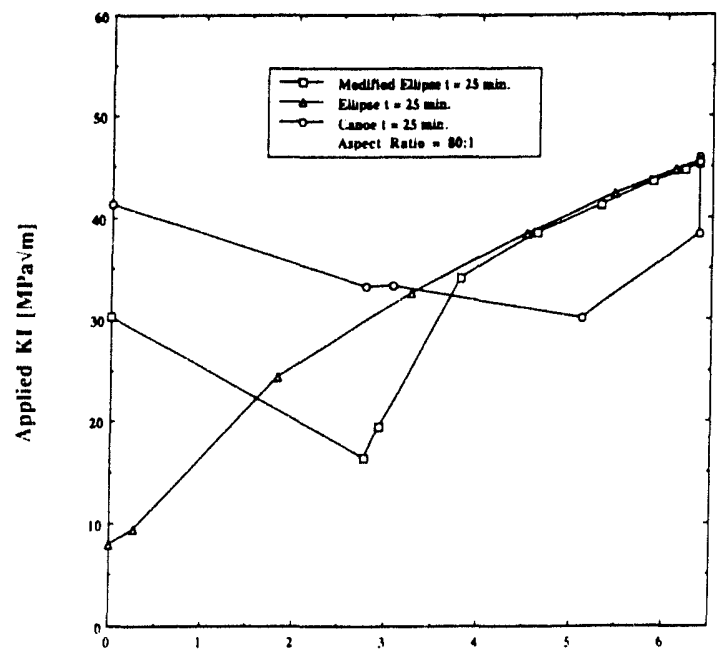

Vessel Wall Depth Measured From Inner-Surface [mm]

Figure 9 Effects of reference flaw geometry on the computed $K_{I}$ values are significant for the case where aspect ratio is 80:1. Results are for $\mathbf{2 5}$ min into the transient

Evidently, potential conversion of an initially 3-D shallow surface flaw to an essentially 2-D axial surface llaw geometry due to PTS loading can be substantially enhanced or inhibited based on the actual llaw geometry during the conversion process. It is cautioned that these results do not provide direct information on which flaw geometry is most likely to exist during the course of crack extension. Furthermore, it is emphasized that while the computed $K_{1}$ values indicated in

Fig. 9 are very sensitive to the llaw geometries investigaled, the differences in llaw geometries are minor in comparison with the overall geometry of the nominal llaw shape. It thus appears that care must be taken to represent the crack front shape realistically near its ends in order to avoid inaccuracies in the value of $K_{I}$ there and thus the tendency for axia! extension.

\subsection{Effects of LEFM vs EPFM Assumptions}

Elfects of linear-clastic vs clastic-plastic description of material response on the computed $\mathrm{K}_{\mathrm{I}}$ values are isolated via a series of scoping calculations involving the inodified elliptical flaw geometry at $25 \mathrm{~min}$ into the transient. The thermoclastic propertics of the base and cladding materials remain as before. In Fig. 10, the true stress-true plastic strain curves adopted for the balse and cladding materials are indicaled. The cladding material is characterized by a bilinear curve with yicld stress $\left(\sigma_{y}\right)=238 \mathrm{MPa}(33.4 \mathrm{ksi})$ and 
ultimate stress $\left(\sigma_{\mathrm{u}}\right)=480 \mathrm{MPal}(69.6 \mathrm{ksi})$. The cladding properties are estimated based on experimental data presented in Rel. 17, which indicate that neither $\sigma_{\mathrm{y}}$ nor $\sigma_{\mathrm{u}}$ is very sensitive to lluence levels up to $5 \times 10^{19} \mathrm{n} / \mathrm{cm}^{2}(\mathrm{E}>1 \mathrm{McV})$ oner the temperature range of 100$\left.)^{\circ} \mathrm{C}-300\right)^{\circ} \mathrm{C}\left(212-572^{\circ} \mathrm{F}\right)$. The batic material is characterized by a multilinear curve with yield stress $\left(\sigma_{y}\right)=388 \mathrm{MPa}(56.3 \mathrm{ksi} \sqrt{\mathrm{in} .})$ and ultimate stress $\left(\sigma_{\mathrm{u}}\right)=617 \mathrm{MPa}(89.4 \mathrm{ksi})$. The basematerial properties correspend to A.533B stecl plate HSST $13-\mathrm{A}$ at 200$)^{\circ} \mathrm{C}(392 \mathrm{~F}){ }^{19}$ Analysis results based on elastic-plastic material description are obtained using a rate-independent, $J_{2}$ (isotropichardening) incremental small strain plasticity formulation as implemented in ABAQUS.

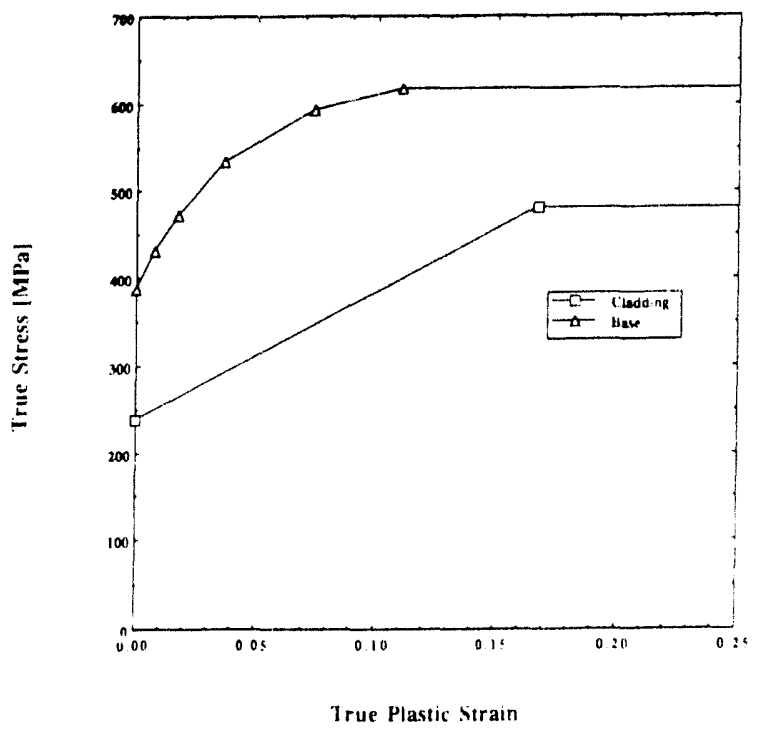

Figure 10 True stress-true plastic strain curves for cladding and base material

In Fig. 11, results are presented lor the cass where the aspect ratio of the modilicd elliptical flaw geometry is $1: 1$. The computed $K_{1}$ values along the cladding portion of the crack front are lower for the calse of elasticplastic material response than the clastc analysis conditions. The opposite arend is secon lor the compuled $K_{I}$ values beyond the chadding region.

In Fig. 12, results ane prescmed for lhe casce where the aspect ratio of the modified elliptical flaw geometry is 8():1. Near the inner-surface along the cladding portion of the crack front, the computed $\mathrm{K}_{1}$ valles are lower for the case of chastic-plastic materal respense than ihe clastic analysis conditions. A similar trend is secon for the computed $\mathrm{K}_{1}$ values along a substantial portion of the crack front within the basc material.

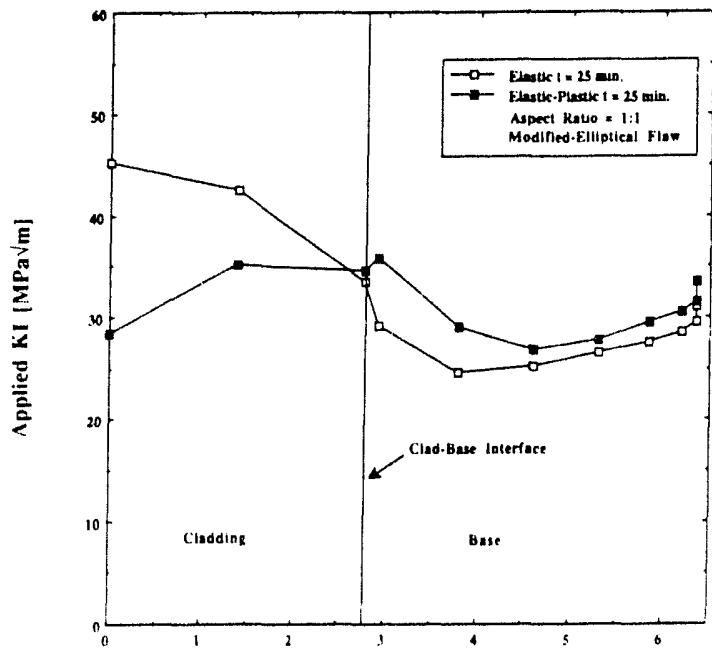

Vessel Wall Depth Measured From Inner-Surface [mm]

Figure 11 Effects of linear-elastic vs elasticplastic description of material response on the computed $k_{I}$ values for the case where the aspect ratio of the modified elliptical flaw geometry is $1: 1$

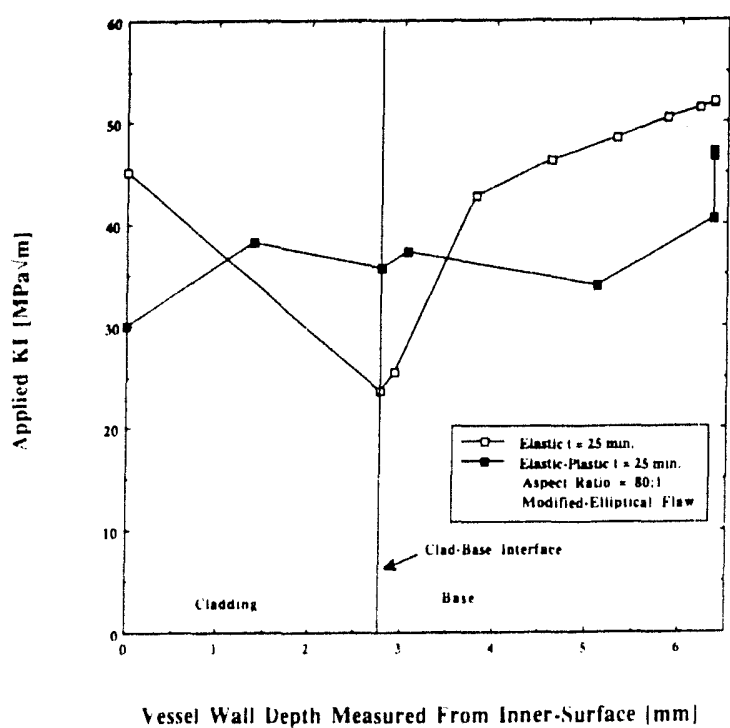

Figure 12 Effects of linear-elastic vs elastic-plastic description of material response on the computed $k_{I}$ values for the case where the aspect ratio of the modified elliptical flaw geometry is $80: 1$

Analysis results in Figs. 11 and 12 thus indicate that the computed $K_{1}$ values are very sensitive to whether the cladding and hase matcrials are modeled as clastic or clastic-plastic, with the latter analysis assumption being more realistic. Near the inner-surface along the cladding portion of the crack liont, the computed $\mathrm{K}_{\mathrm{I}}$ values are lower for the casce of elastic-plastic than clastic material response. Within the base material, the 
relative ordering depends on the aspece ratio of the flaw.

The lower $\mathrm{K}_{\mathrm{I}}$ values associated with elastic-plastic conditions, relative to lincar-elastic conditions, near the inner-surface along the cladding portion of the crack front can be readily explained in terms of the lower resultant stresses (or tractions) that develop over that region. The lower resultant stresses are due to the imposition of a finite value of the yield stress under clastic-plastic conditions and the fact that the cladding yield stress is substantially lower than that for the base material. Similar observations have been reported in Ref. 2 ().

Comparison of the results show'n in Figs. 11 and 12 suggests that, as the nominal law shape in terms of the overall aspect ratio increases, the assumption of clastic-plastic material response leads to the maximum $\mathrm{K}_{\mathrm{I}}$ value being located away from the inner-surface of the vessel toward the deepest point of the crack front. Migration of the location of maximum $\mathrm{K}_{1}$ loward the decpest point of the crack front is suggestive of an enhanced tendency toward radial rather than axial crack propagation and, therefore, lessens the likelihood of the conversion of an initially 3-D shallow surfice llaw (o) an essentially $2-D$ axial flaw geometry.

One aspect concerning the inclusion of plasticity effects in evaluating the propensity for crack initialion that has not been considered in this study is the role of crack-tip constraint as characterized by the Q-stress parameter. 21-23 Available experimental data for shallow through-thickness surface llaw's of depths $\sim 10$ $\mathrm{mm}(0.4$ in.) under mechanical three-point-bend loading suggest that cohanced fracture toughness is associated with this shallow-llaw geometry, and that the so-called shallow-llaw loughness cllect can be related to the role of the nonsingular hydrostatlic Q-stress as a descriptor of crack-tip constraint. 24,25 Limiled analytical results have been obtained lor the crack-lip fields associated with a shallow $(\sim 10 \mathrm{~mm}) 2-\mathrm{D}$ surface flaw in a thermally shocked cylinder and in a PWR RPV during the coursc of a PTS transicmt. 16,24,26,27 These analytical results suggest that an clastie-plastic, J-Q-based description of the crack-driving force provides a more appropriate framework lor evaluating the fracture response of a PWR - RPV during a PTS transient than conventional single parameter ( $K$ - or J-only) methods under elastic or elastic-plastic condations.

\subsection{Effects of Base-Material-Only vs Cladding-Base Vessel- Model Assumptions}

Ellects of modeling the RPV as either base-materialonly or as a bimaterial cladding-base vessel on the computed $\mathrm{K}_{\mathrm{I}}$ values are examined via a series of scoping calculations in this section. Material models of the RPV considered are (1) clastic base and cladding matcrial [bimaterial elastic (Bi-El)], (2) clastic base with cladding material assigned base material propertics (base-only clastic (Basc-El)), and (3) clasticplastic base and cladding material / bimaterial elasticplastic (Bi-Ep)]. Note that for the present analysis conditions, the vessel through-wall temperature profile is minimally affected by the assumption of cladding (stainless steel) or base (A.533B steel) material thermal propertics. The primary effect of either a basematcrial-only or a bimaterial assumption in the cladding region concerns the value of the thermal expansion coefficient in the case of an elastic analysis and the additional influence of the stress-strain curve in the case of an elastic-plastic analysis.

In Fig. 13, results are presented for the case where the aspect ratio of the modificd elliptical liaw geometry is $1: 1$. It is observed that assumption of a base-materialonly clastic model results in lowest values of the computed $\mathrm{K}_{\mathrm{I}}$ values almost every where along the crack front. In Fig. 14, results are presented for the case where the aspect ratio of the canoe llaw geometry is 8()$: 1$. Again, it is observed that assumption of a basematcrial-only elastic model results in lowest values of the computed $\mathrm{K}_{1}$ values almost every where along the crack fronl.

From Figs. 13 and 14, the assumption of an clastic base-metal-only model of an RPV, as compared to cither an elastic clad-base metal or an clastic-plastic clad-barse metal model, is secn to result in lowest computed $K_{1}$ values almost everywhere along the crack iront. Consequently, analy'sis of the satety margin of an RPV with respect to PTS loading based on a simplified clastic base-metal-only model is nonconservative. It is noted that current guidelines do in fact require that the thermo-mechanical properties of the cladding material be included in a plant-specilic PTA analysis.! 


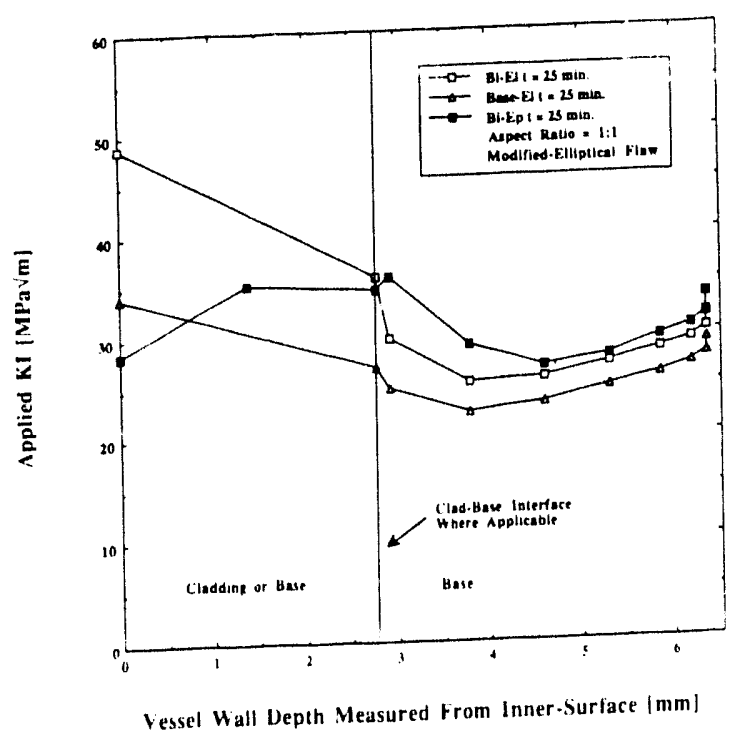

Figure 13 Effects of vessel-model assumptions on the computed $K_{I}$ values for the case where the aspect ratio of the modified elliptical flaw geometry is $1: 1$

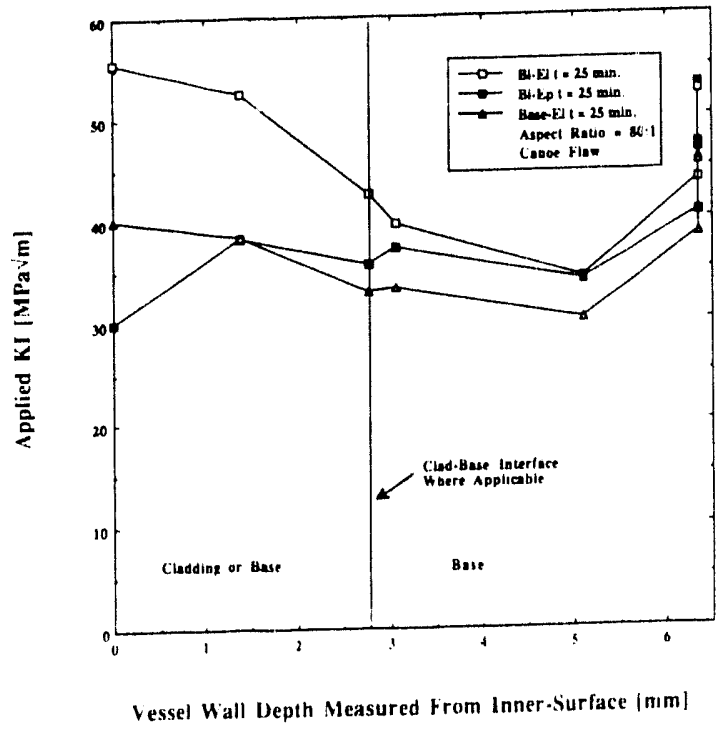

Figure 14 Effects of vessel-model assumption on the computed $K_{I}$ values for the case where the aspect ratio of the canoe flaw geometry is 80:1 


\section{Conclusions}

From the first part of this study, based on LEFM assumptions and considering only a family of modified clliptical flaws, the following conclusions are drawn.

A. Within the context of the interpretation method outlined here, whether a flaw will tend to extend exclusively in either the axial or depth direction or a combination of both directions is strongly dependent on the the $\mathrm{K}_{\mathrm{I}}$ values along the crack front and the gradient of fracture toughness through the vessel wall at the time of initiation.

B. If one assumes that the cladding shares the ..... Iness of the base material, preliminary results from this study indicate that for the assumed fracture toughness and initial flaw geometry, the ncarly semicircular flaw would likely propagate in the axial direction in an unrestrained manner during the transient followed by propagation into the wall of the vessel. W'ithout additional calculations it is not possible to conclude whether the flaw would arrest in the depth direction. Note that these results correspond to initiation within the lowershelf fracture toughness temperature range, and that their general validity within the lowertransition temperature range remains to be determined.

C. A 3-D, nearly semicircular, finite-length flaw has less potential for initiation than a 2-D flaw of the same depth for the conditions examined in this study. However, since the finite-length flaw is still expected to extend along the entire length of the vessel during the transient, the conservatism associated with the use of a 2-D flaw geometry is of no consequence in the present deterministic: evaluation. However, note that this observation has general applicability only when warm prestress effects are not considered. Furthermore, without additional calculations it is not possible to quantify this type of conservatism in a probabilisiic cvaluation.
D. Available experimental data indicate that the cladding may be tougher than the base material. When this observation is incorporated into the interpretation method, the results from this study suggest that a nearly semicircular flaw would not initiate during the course of the PTS transient for the conditions examined in this study. The assumption of cladding toughness higher than that of the base material thus appears to represent one avenue through which the tendency for $3-D$, finitelength flaws to convert to essentially 2-D surface flaws could be inhibited. A related mechanism for inhibiting the conversion to 2-D surface flaws is the formation of subclad flaws.

From the second part of this study, which is focused on various analysis sensitivity issues, the following conclusions are drawn.

A. Analysis results suggest that the crack-front geometry within the cladding can significantly influence the computed $\mathrm{K}_{\mathrm{I}}$ values along the crack front within the cladding region, especially for the case of clongated surface flaws with large aspect ratios. The computed $\mathrm{K}_{\mathrm{I}}$ values along the crack front within the cladding region increase with increasing curvature of the crack front in that region.

B. Analysis results indicate that the computed $\mathrm{K}_{\mathrm{I}}$ values are very sensitive to whether the cladding and base materials are modeled as clastic or clastic-plastic, with the latter analysis assumption being more realistic. Near the inner-surface along the cladding portion of the crack front, the computed $K_{I}$ values are lower for the case of elasticplastic than elastic material response. Within the base material, the relative ordering depends on the aspect ratio of the flaw.

C. The assumption of an elastic base-metal-only model of an RPV, as compared to cither an clastic clad-base metal or an clastic-plastic clad-base metal model, results in lowest computed $\mathrm{K}_{\mathrm{I}}$ values almost everywhere along the crack front. Consequently, analysis of the safety margin of an RPV with respect to PTS loading based on a simplified clastic base-metal-only model is nonconservative. 


\section{References}

1. U.S. Nuclear Regulatory Commission, Regulatory Guide 1.154, "Format and Content of Plant-Specilic Pressurized Thermal Shock Safety Analysis Reports for Pressurized Water Reactors."*

2. T. J. Burns et al., Martin Marietta Energy Systems, Inc., Oak Ridge Natl. Lab., Pressurized Thermal Shock Evaluation of the Oconee-1 Nuclear Power Plant, USNRC Report NUREG/CR-3770 (ORNL/TM-9176), May 1986. ${ }^{\dagger}$

3. D. L. Sclby et al., Martin Marictla Energy Systems, Inc., Oak Ridge Nall. Lab., Pressurized Thermal Shock Evaluation of the Calvert Cliffs Unit I Nuclear Power Plant, USNRC Report NUREG/CR-4)22 (ORNL/TM94(08), September 1985. ${ }^{\dagger}$

4. D. L. Selby et al., Martin Mariclia Energy Systems, Inc., Oak Ridge Natl. Lab., Pressurized Thermal Shock Evaluation of the II. B. Robinson Unit 2 Nuclear Power Plant. USNRC Report NUREG/CR-4183 (ORNL/TM9567), Vols. 1 and 2, September $1985^{\dagger}$

5. R. D. Cheverton et al, Martin Mariella Energy Systems, Inc., Oak Ridge Natl. Lab., Pressure Vessel Fracture Studies Pertaining to the PWR Thermal-Shock Issue: Experiment TSE-7, USNRC Report NUREG/CR-4304 (ORNL6177), August 1985.

6. R. D. Cheverton, Martin Marielta Energy Systems, Inc., Oak Ridge Nall. Lab., Pressure Vessel Fracture Studics Pertaining of a PWR LOCA-ECC Thermal Shork: Experiments TSE$I$ and TSE-2, USNRC Reporl ORNL/NUREG/TM-31, September 1976.

7. D. K. M. Shum et al., Martin Marietla Energy Systems, Inc., Oak Ridge Nall. Lab., Poten'i,ll Change in Flaw Geometry of an Initially Shallow, Axially Oriented, Inner-Surface FiniteLength Flaw During a Pressurized-ThermalShock Transient, USNRC Report ORNL/NRC/LTR-92/11, January, 1992. * *

\footnotetext{
* Available in public technical libraries.

† Available for purchase from the National Technical Information Service, Springfield, VA 22161.

$\mp$ Available in NRC Public Document Room.
}

8. D. K. M. Shum et al., Potential Change in Flaw Geometry During Pressurized-Thermal-Shock Transients Paper to be presented at ASME Pressure Vesscl and Piping Divison Conference, Denver, CO (July 1993),

9. The American Society of Mechanical Engineers Boiler and Pressure Vessel Code, Section XI, Rules for Inservice Inspection of Nuclear Power Plant Components, Appendix A, "Analysis of Flaws," Article A-4(0)(), Material Propertics, 1989. $\ddagger$

10. U.S. Nuclear Regulatory Commission, Regulatory Guide 1.99, Revision 2, "Radiation Embrittlement of Reactor Vessel Materials," May $1988 .{ }^{*}$

11. B. R. Bass and J. W. Bryson, Martin Marietla Energy Systems, Inc., Oak Ridge Natl. Lab., ORMGEN-3D: A Finite-Element Mesh Generator for 3-Dimensional Crack Geometries, USNRC Report NUREG/CR2997/VI (ORNL/TM-8527), December 1982.

12. R. D. Cheverton and D. G. Ball, Martin Marietta Energy Systems, Inc., Oak Ridge Natl Lab., OCA-P. A Deterministic and Probabilistic. Fracture-Mechunics Code for Application to Pressure Vessels, USNRC Reporl NUREG3618 (ORNL-5991), May 1984. ${ }^{\dagger}$

13. ABAQUS User Manual, Version 4-9-1, Hibbit, Karlsson \& Sorensen, Inc., Providence, Rhode Island, 1991.

14. ADINA -... Automatic: Dynamic Incremental Nonlinear Analysis, Report ARD 87-1, ADINA R\&D, Inc., Watertown, MA, December, 1987.

15. B. R. Bass and J. W. Bryson, Martin Marictla Energy Systems, Inc., Oak Ridge Nall. Lab., ORVIRT: A Finite-Element Program for Energy Release Rate Calculations for 2-Dimensional and 3-Dimensional Crack Models, USNRC Report NUREG/CR-299/V2 (ORNL/TM-8.527), February 1983. ${ }^{\dagger}$

16. D. K. M. Shum, Martin Maricua Energy Systems, Inc., Oak Ridge Natl. Lab., Preliminary investigation on the Inclusion of Warm Prestress Effects in Fracture-Margin Assessment of Recuctor Pressure Vessels, USNRC Report NUREG/CR-5946 (ORNL/TM12236), draft available from D. K. M. Shum. 
17. F. M. Haggag, W. R. Corwin, and R. K. Nanstad, Martin Marietla Energy Systems, Inc., Oak Ridge Natl. Lab., Irradiation Effects on Strength and Toughness of Three-Wire SeriesArc Stainless Steel Weld Overlay Cladding, USNRC Report NUREG/CR-5511 (ORNL/TM11439), Fcbruary 1990. ${ }^{\dagger}$

18. R. D. Cheverton et al., "Thermal-Shock Experiments with Flawed Clad Cylinders," Nucl. Eng. and Des. 124, 1(9)-119, (1990)."

19. D. J. Naus et al., Martin Mariclla Energy Systems, Inc., Oak Ridge Natl. Lab., CrackArrest Behavior in SEN Wide Plates of Quenched and Tempered A.533 Grade B Steel Tested Under Nonisothermai Conditions. USNRC Report NUREG/CR-4930)(ORNL6388), August 1987.

20. I. Sattari-Far, "3-Dimensional Elastic-Plastic FE-Analyses of Cladded Reactor Pressure Vessels Containing Surlace Flaws," $A S M E$ Pressure Vessels and Piping Division Conference, PVP Vol. 213/MPC 32, American Society of Mechanical Engineers (June 1991).*

21. N. P. O'Dowd and C. F. Shih, "Family of CrackTip Fields Characterized by a Triaxiality Parameter: Part I - Structure of Ficlds," Journal of the Mechanics and Physics of Solids, 39, 989-1015 (1991).

22. N. P. O'Dowd and C. F. Shih, "Family of CrackTip Ficlds Characterized by a Triaxiality Parameter: Part II - Fracture Applications," Journal of the Mechanics and Physics of Solids, 40, 939-963, (1992).
23. C. F. Shih and N. P. O'Dowd, "A Fracture Mechanics Approach Based on a Toughness Locus," Proceedings of the International Conference on Shallow Crack Fracture Mechanics Tests and Applications, Cambridge, U.K., (September 1992). ${ }^{*}$

24. T. J. Theiss, D. K. M. Shum, and S. T. Rolfe, Martin Mariella Energy Systems, Inc., Oak Ridige Nall. Lab., Experimental and Analytical Investigation of the Shallow-Flaw Effect in Reactor Pressure Vessels, USNRC Repon NUREG/CR-5886 (ORNL/TM-12115), July $1992 .^{\dagger}$

25. T. J. Theiss, D. K. M. Shum, and S. T. Rolfe, "Interim Results from the HSST Shallow-Crack Fracture Toughness Program," paper presented at the 24th National Symposium on Fracture Mechanics, Gallinburg, TN (July 1992).

26. D. K. M. Shum and B. R. Bass, Absence of Toughnexs Elevation in Thermal-Shock Experiment TSE-5A: Preliminary Explanation Based on Crack-Tip Constraint, ORNL/NRC/L.TR-92/24, available from D. K. M. Shunil.

27. D. K. M. Shum, T. J. Theiss, and S. T. Rolfe, "Application of J-Q Fracture Methodology to the Analysis of Pressurized-Thermal-Shock in Reactor Pressure Vessels," paper presented at the 24th National Symposium on Fracture Mechanics, Gallinburg, TN (July 1992). 


\section{Appendix A}

\section{Closed-Form Solutions for $\mathrm{K}_{\mathrm{I}}$ for a Shallow Elliptical Surface Flaw in a Plate}

Essentially closed-form solutions for $\mathrm{K}_{\mathrm{I}}$ for a shallow elliptical surface flaw in a plate are available in the literature. ${ }^{1-4, *}, \dagger$ These closed-form solutions are applicable under LEFM conditions and require that the distribution of tractions normal to the "crack face" in the usual "cut-and-release" sense be provided as input. In the following discussion, both the thermal analysis and the resultant distribution of tractions are obtained from the computer code OCA.P, such that the closedform solutions are obtained in a manner completely independent of the finite-element models or the computer code ABAQUS.

In the closed-form calculations indicated in Table A.1, the RPV is modeled as a linear-elastic bimaterial vessel with an elliptical flaw geometry. Values are obtained at both the deepest point of the crack and at the inner surface of the vessel at $25 \mathrm{~min}$ into the transient. Both the $1: 1$ and 80:1 aspect ratios are considered.

Validation of the finite-element results with the closedform solutions is approximate in nature because the "bimaterial/clliptical flaw" combination was not examined as part of the finite-element analysis matrix because of practical limitations in the mesh-generation program. However, the "bimaterial/modified elliptical flaw" and "base-material-only/elliptical flaw" combinations were considered as part of the finiteclement analysis matrix. This slightly indirect validation is useful in checking the value of $\mathrm{K}_{\mathrm{I}}$ at the decpest point of the crack in Figs. 6, 8, 9, and 11-13 and in confirming the relative ordering of $\mathrm{K}_{I}$ values at the inner surface of the vessel in Fig. 13.

\section{References}

1. F. W. Smith, A. F. Emery, A. S. Kobayashi, "Stress Intensity Factors for Semicircular Cracks. Part 2 - Semi-Infinite Solid," Paper No. 67. WA/APM 2, Iournal of Applied Mechanics, American Socicly of Mechanical Enginecrs (December 1967) $\ddagger$

2. J. G. Merkle, Martin Marictla Encrgy Systems, Inc., Oak Ridge Natl. Lab., A Review of Some of the Existing Stress Intensity Factor Solutions for Part-Through Surface Cracks, ORNL-TM-3983 January 1973.

3. J. G. Merkle, Martin Marictla Energy Systems, Inc., Oak Ridge Natl. Lab., "Stress Intensity Factor Estimates for Part-Through Surface Cracks in Plates Under Combined Tension and Bending," pp. 3-22 and 31-32 in Heavy-Section Steel Iechnology Program Quart. Prog. Rep. JulySeptember 1974, ORNL-TM-4729, Vol. II, Union Carbide Corp. Nuclear Div., Oak Ridge Natl. Lab., November 1974.

4. J. C. Newman and I. S. Raju, "Stress-Intensity Factor Equations for Cracks in Threc-Dimensional Finite Bodies Subjected to Tension and Bending Loads," Chapter 9 in Computational Methods in the Mechunics of Fracture, S. N. Atluri (ed.), Elscvier Science Publishers B.V., 1986.

* R. Cipolla, Revision of $K_{1}$ Sect., Supporting Figs., ASME, Section XI WGFE, $11 / 19 / 91$.

${ }^{+}$R. Cipollas, Proposed Revisions to $K_{1}$, ASME WGFE, $11 / 19 / 91$.

$\ddagger$ Available in public technical libraries. 
Table A.1 Closed-form solutions for $K_{I}$ at two locations along the crack front for the "bimaterial/elliptical flaw" combination

\begin{tabular}{ccc}
$\begin{array}{c}\text { Flaw } \\
\text { half-length } \\
(\mathrm{mm})\end{array}$ & $\begin{array}{c}\text { Deepest point } \\
\mathrm{K}_{\mathrm{I}} \\
(\mathrm{MPa} \sqrt{\mathrm{m}})\end{array}$ & $\begin{array}{c}\text { Surface } \\
\mathrm{K}_{\mathrm{I}} \\
(\mathrm{MPa} \sqrt{\mathrm{m}})\end{array}$ \\
\hline 6.35 & $29.8^{1,2}$ & $44.8^{1,2}$ \\
$(1: 1)$ & $30.8^{3,4}$ & $41.1^{3,4}$ \\
\hline 508 & $58.7^{1,2}$ & $7.86^{1,2}$ \\
$(80: 1)$ & $53.8^{3,4}$ & $8.013,4$ \\
\hline
\end{tabular}




\section{Appendix B}

\section{Effects of Mesh Refinement on $K_{I}$ Values Along the Crack Front}

\section{Circumferential Stiffiness of Vessel}

Axial flaws are considered in this study.

Consequently, accurate calculations of $K_{1}$ values allong the crack front reyuires that the circumferential stiffness of the vessel be properly modeled. The eflects of mesh refinement in the circumferential direction on the calculated $\mathrm{K}_{\mathrm{I}}$ values are examined by successively modeling the circumferential extent of the vessel with six, ten and twelve elements. In all three calses, the element size increases geometrically in the circumlerential direction as indicated in Fig. 2(a). The model in Fig. 2(a) has ten clenents in the circumferential direction. In the following comparison, the cladding region is represented by onc layer of elements and the aspect ratio of the modified elliptical flaw geometry is $1: 1$.

In Fig. B. 1, results are indicalled at $25 \mathrm{~min}$ into) the transient. It is observed that the calculated $k$ / values are very sensilive to mesh refinement in the circumfer. ential direction. The $K_{l}$ values increase by $\leqslant(0) \%$ als the model is refined from sis to ken elements. The $\mathrm{K}_{1}$ values further increase by $56 \%$ as the model is refined from ten to twelve elements. Balsed on the evident slower rate of change in the $K_{1}$ values as the model is refined from ten to twelve elements, it is believed that the vessel can be adequately modekd with a minimum of ten elements in the circumferential direction.

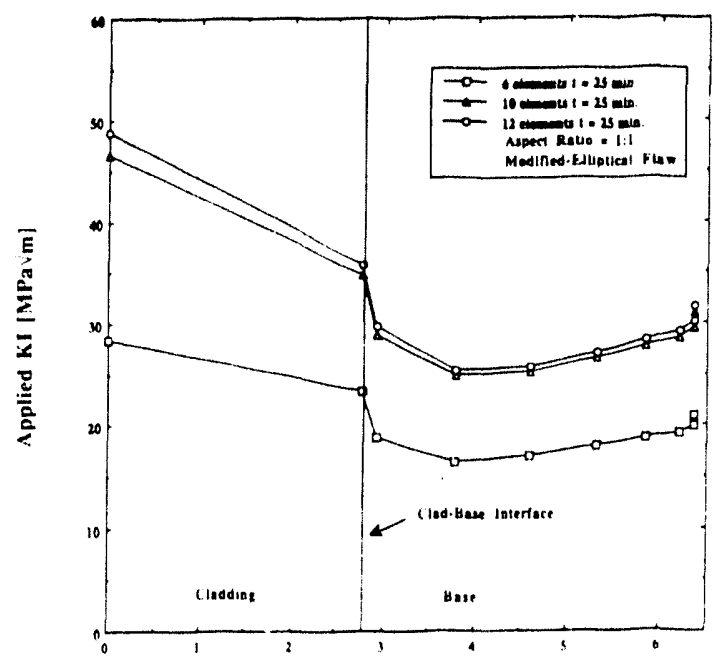

Vessel Wall Depth Measured from Inner-Surface $\mid \mathrm{mm}$ |

Figure B.1 Effects of mesh refinement in the circumferential direction of the vessel on the computed $\mathrm{K}_{1}$ values

\section{Refinement in Cladding Region}

In this study, all flaw geometries employ a common flaw depth of $6.35 \mathrm{~mm}(0.25 \mathrm{in}$.). The cladding region has a thickness of $2.769 \mathrm{~mm}(0.109$ in.). Since the cladding thickness is significant relative to the flaw depth, an accurate calculation of the $\mathrm{K}_{I}$ values along the crack front requires that the stress distribution within the cladding region be accurately determined. The eflects of mesh refinement for modeling the behavior of the cladding on the caiculated $\mathrm{K}_{1}$ values is examined with models in which the cladding is represented with alternately a single layer or two or four layers of elements. In the following comparisons, the aspect ratio of the modified elliptical flaw geometry is $1: 1$.

In Fig. B.2, results are indicated at $2.5 \mathrm{~min}$ into the transient for models with one or $t w 0$ elements in the cladding region and ten elements in the circumferential direction of the vessel. No significant effect on the calculated $K_{1}$ values along the crack front is observed. In Fig. B. 3, results are indicated at 25 min into the transient for models with one or four elements in the cladding region and six clements in the circumferential direction of the vessel. Again, no significant effect on the calculated $\mathrm{K}_{1}$ values along the crack front is observed. The refinement insensitivity observed in Figs. B.2 and B.3 is a direct consequence of the observation that the distribution of (normal) tractions within the cladding region is essentially linear with wall depeh.

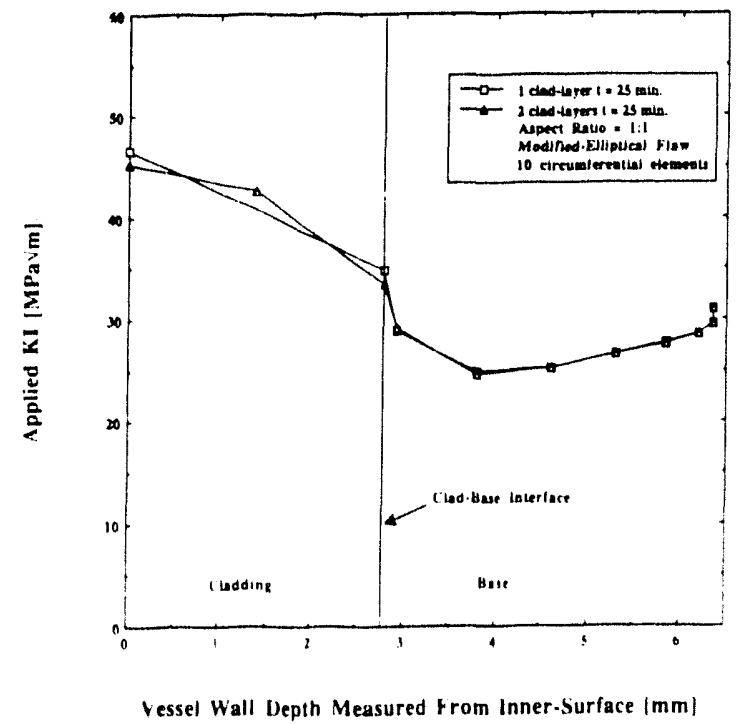

Figure B.2 Effects of one or two layers of elements in the cladding region on the computed $K_{1}$ values 


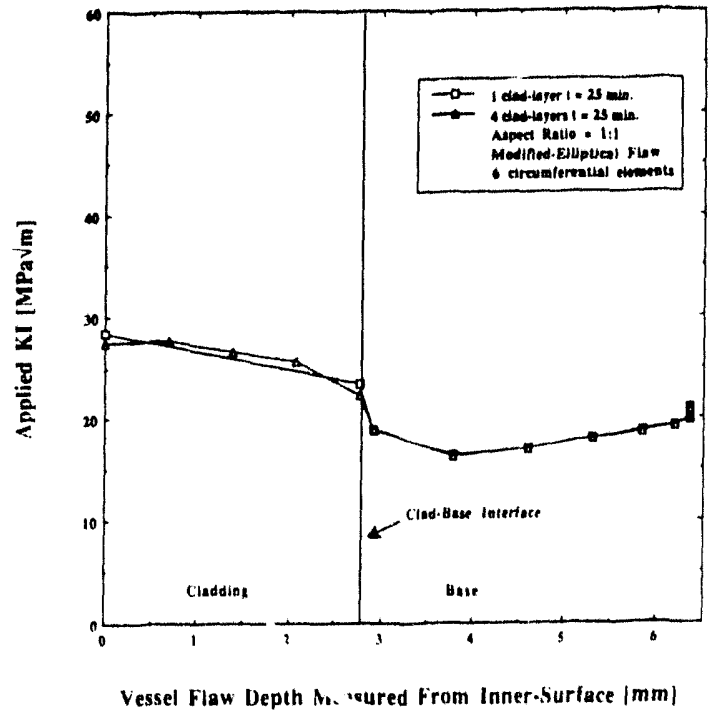

Figure B.3 Effects of one or four layers of elements in the cladding region on the computed Ki values

As discussed in Sect. 4 of this paper, the calculaled $K_{1}$ values within the cladding region are very sensitive 10 the shape of the llaw within the cladding region near the inner-surface of the vessiel. Conseguently, it is cmphasized that the observed refinement insensitivity is strictly applicable only to the modilicd-clliptical liaw geometry examined. Additiomal calculations are needed to evaluate the generality of this ubservalion to other flaw geometries.

\section{Influence of Finite Vessel Axial Length}

Analysis results presented in the main body of this study are based on a vessel axial length of $152 \mathrm{~cm}(60)$ in.), which is representative of the extent of the belt. line region in a PWR - RPV. The total length of the RPV is, of course, much grealter. In the case of flaws with an aspect ratio of $1: 1$, it is expected that the values would not change if the axial length is $>1.52 \mathrm{~cm}(60)$ in.). This may not be the case for llaws with an aspect ralio of 8(): 1. Consequently, a limited number of analyses involving the modified ellipse and the canoe llaw geometry have been carried out to exannine the in. fluence of vessel axial length on the calculated $\mathrm{K}_{\text {I }}$ values along the crack front in the case of a llaw geometry with an aspect ratio of $8(0) 1$. These additional analyses are based on a vessel axial length of $3(14 \mathrm{~cm}(120 \mathrm{in}$.$) , and the finite-element models are$ constructed by suitably "stretching" the ends of the 60)in.- long finite-element models. No additional finiteclements are incorporated. In all cases examined, minimal influence of vessed axial length on the calculated $\mathrm{K}_{\mathrm{I}}$ values along the crack front is observed. 
Internal Distribution

1. D. J. Alexander

2. B. R. Bass

3. J. W. Bryson

4. E. W. Carver

5-6. R. D. Cheverton

7. J M. Corum

8. W. R. Corwin

9. T. L. Dickson

10. F. M. Haggag

11. J. J. Henry

12. W. F. Jackson

13. J. E. Jones Jr.

14. S. K. Iskander

15. J. A. Keeney

16. W. J. McAfce

17. D. E. McCabe
18. J. G. Mcrkle

19. R. K. Nanstad

20. D. J. Naus

21-25. W. E. Pennell

26. C. B. Oland

27. C. E. Pugh

28. M. C. Rao

29. D. K. M. Shum

30. R. L. Swain

31-34. T. J. Thciss

35. E. W. Whitficld

36. ORNL Patent Section

37. Central Rescarch Library

38. Document Reference Section

39-40. Laboratory Rccords

41. Laboratory Records (RC)

\section{External Distribution}

42. L. C. Shao, Director, Division of Engincering, U.S. Nuclear Regulatory Commission

43. C. Z. Serpan, Jr., Division of Engincering, U.S. Nuclear Regulatory Commission

44. E. M. Hackett, Matcrials and Chemical Engincering Branch, U.S. Nuclear Regulatory Commission

45. A. L. Hiscr, Division of Enginecring, U.S. Nuclear Regulatory Commission

46-48. S. N. Mi. Malik, Division of Engincering, U.S. Nuclear Regulatory Commission

49. M. E. Mayficld, Division of Enginecring, U.S. Nuclear Regulatory Commission

50. A. Taboada, Division of Enginecring, U.S. Nuclcar Regulatory Commission

51. J. W. Dally, Department of Mechanical Enginecring, Universily of Maryland, College Park, MD 20742

52. G. R. Irwin, Department of Mechanical Engineering, Universily of Maryland, College Park, MD 20742

53. L. James, Westinghousc Bcliis Lab., P.O. Box 79, ZAP 13A, 814 Pillsburgh McKecsport Blvd., West Mifflin, PA 15122

54. C. F. Shih, Box D, Division of Enginecring, Brown University, Providence, RI 02912

55. R. Dodds, 3140 Newmark Laboratory, 205 North Mallhews, Urbana, IL 61801

56. R. Fields, National Inst. of Standards and Technology, Bldg. 223, B 144, Gaithersburg, MD 20899

57. W. L. Fourncy, Department of Mechanical Engincering, University of Maryland, College Park, MD 20742

58. J. D. Landes, The Universily of Tennessec, Knoxville, TN 37996-2030

59. S. T. Rolfc, The Universily of Kansas, Lawrence, KS 66()45-2235

60. A. R. Rosenficld, Ballelle Columbus Division, Columbus, $\mathrm{OH} 43201$

61. C. W. Schwart\%, Department of Civil Enginecring, University of Maryland, College Park, MD 20742

62. E. T. Wessel, 312 Wolverine, Haines Cily, FL 3.3844

63. Office of Assistant Manager for Encrgy Rescarch and Development, DOE-ORO, Oak Ridge, TN 37831

64. Commander and Director USAE Walcrways Experiment Station, Altn: CEWES-INi-MI-R, Alfricda S. Clark, CD Dept./\#1072. 3909) Halls Ferry Road, Vicksburg, MS 39180-6199

65-66. Office of Scientific and Technical Inlormation, P. O. Box 62, Oak Ridge, TN 37831 

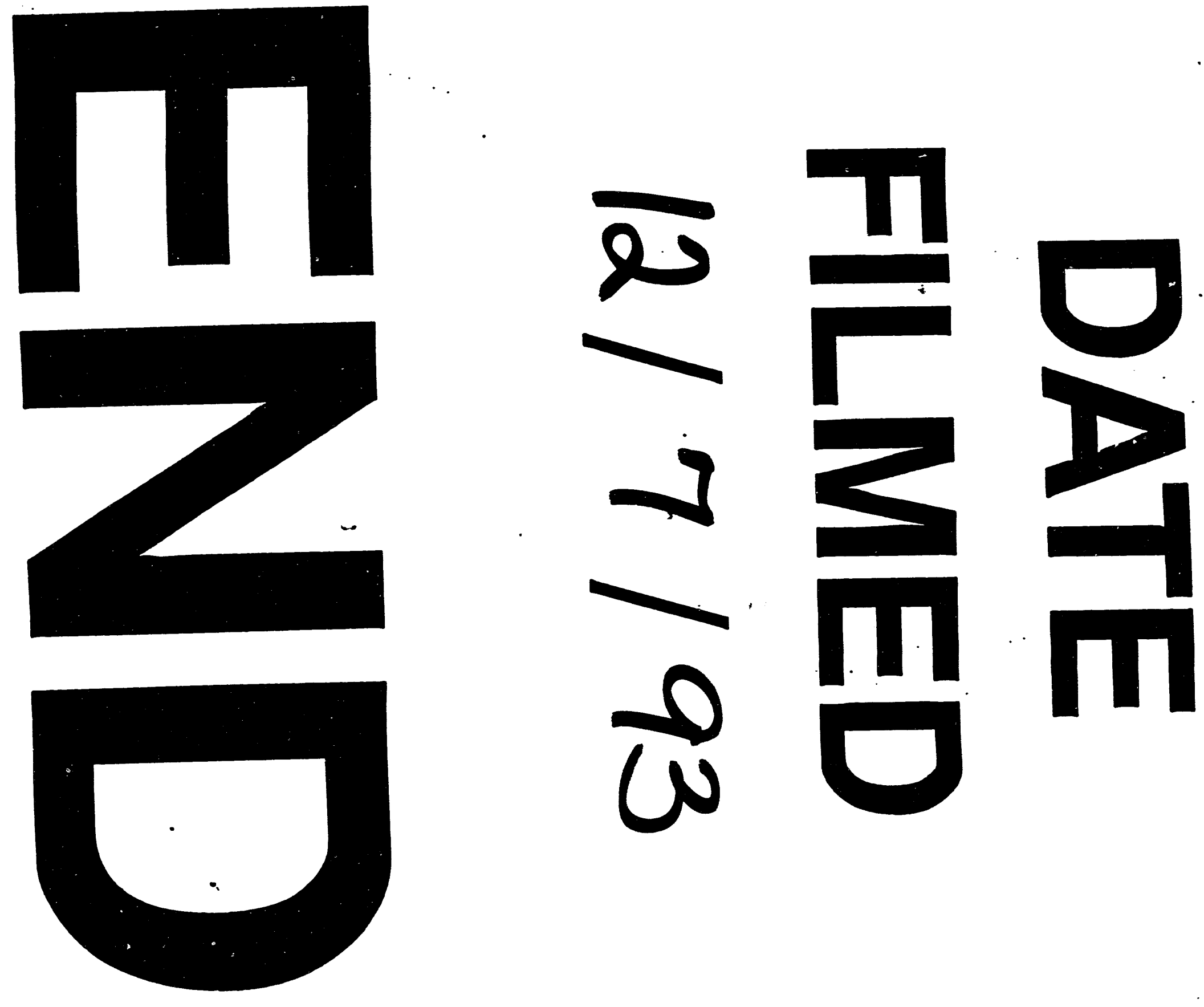
